\title{
Peter Scholz
}

\section{Elementarunterricht und intellektuelle Bildung im hellenistischen Gymnasion}

Allzu häufig wurde und wird die Institution des Gymnasions auf ihre Funktion als 'Bildungszentrum' oder, weiter gefaßt und zurückhaltender formuliert, als 'Kulturzentrum'1 reduziert. Dieser Auffassung zufolge stellt das Gymnasion ein städtisches, die Staatlichkeit repräsentierendes Erziehungsinstitut dar, das der Jugend in den meisten griechischen Städten zumindest einen streng reglementierten Unterricht in mehreren Fächern, wenn nicht sogar ein philosophisches Propädeutikum zuteil werden ließ. Entsprechend wurde das Gymnasion in der Forschung lange Zeit gerne als eine Stätte wissenschaftlicher Ausbildung und Tätigkeit dargestellt und in manchen Fällen sogar als ein Vorläufer der modernen Universität bezeichnet, an der bereits alle Spielarten des damals bekannten Wissens gelehrt worden seien. ${ }^{2}$

Mein Beitrag wendet sich nachdrücklich gegen diese die modernen Verhältnisse in die historische Evidenz hineingetragenen, jedoch weit verbreiteten und so auch in vielen älteren Handbüchern und monographischen Abhandlungen anzutreffenden Vorstellungen, denen letztlich eine allzu optimistische Einschätzung von der Verbreitung von Literalität und Wertschätzung intellektueller Bildung in den hellenistischen Städten zugrundeliegt. Die nachstehende Untersuchung versucht der einseitig akzentuierten Auffassung des Gymnasions als einer seitens der Städte immer schon geschützten und geförderten Institution des griechischen Geisteslebens entgegenzutreten und anhand der vorliegenden, vor allem epigraphischen Zeugnisse ein realistischeres, wenn auch nicht unbedingt neues Bild ${ }^{3}$ von den intellektuellen Aspekten des hellenistischen Gymnasialbetriebs auf der Basis der vorhandenen, vor allem epigraphischen Quellen nachzuzeichnen: Keineswegs nämlich war die intellektuelle Erziehung notwendigerweise an den Besuch einer öffentlichen Institution wie die des Gymnasions geknüpft. Gerade im Fall von Jugendlichen vornehmer Abkunft war die private Erziehung im familiären Umfeld durch Hauslehrer üblich. ${ }^{4}$ Diese standen in der Regel in sozialer Abhängigkeit zu den betreffenden Familien und waren als Sklaven oder Freigelassene eng an die letzteren gebunden. Darüber hinaus gab es in den griechischen Städten

Für die kritische Lektüre des Manuskripts, für vielfältige Anregungen, Änderungs- und Ergänzungsvorschläge möchte ich Klaus Bringmann, William V. Harris, Daniel Kah, Hartmut Leppin, Christof Selzer und Michael Wörrle herzlich danken.

$1 \mathrm{Vgl}$. anstelle von anderen: SCHNEIDER: Kulturgeschichte I, 138. So etwa auch jüngst wieder sehr prononciert: WACKER: Gymnasion in Olympia, 131-137.

2 So etwa DELORME: Gymnasion, 316.

3 In diesem Sinne bereits: HADOT, DNP "Gymnasion II", 23, die sich im Rahmen des Lexikoneintrags mit der allgemein gehaltenen Bemerkung begnügen muß, daß die Jugend weder im Hellenismus noch in der Kaiserzeit im Rahmen des allgemeinen Gymnasionsbetriebs in die artes liberales eingeführt worden wären. 4 Nach wie vor grundlegend hierzu: FERDINAND MAHIR: Geist und Wert der Familienerziehung im Altertum, Diss. München, Oettingen 1928. 
eine Vielzahl privater 'Schulen', oder besser gesagt, verschiedenste Angebote der Unterrichtung in der Gruppe für die einzelnen Altersstufen, die vom Elementarunterricht bis hin zu rhetorischen oder philosophischen Übungen und Kursen reichen konnten. Diese verschiedenen Formen der Unterrichtung wurden entweder auf privaten Grundstücken und Räumlichkeiten, insbesondere in den Palästren vornehmer Häuser, abgehalten oder auf öffentlichen Plätzen und in Gebäuden, die der Allgemeinheit zugänglich waren (etwa in Stoen, Theater, Odeien, Gymnasien etc.). Weil wir schon aufgrund der spärlichen Überlieferung nur selten in der Lage sind, genau zu bestimmen, an welchem Ort jeweils gelehrt wurde, zumal, wie das Beispiel der Stoiker in Athen zeigt, an verschiedenen Lokalitäten unterrichtet werden konnte, sind für die nachstehende Darstellung auch durchaus Zeugnisse für die Vermittlung intellektueller Bildung berücksichtigt, in denen das Gymnasion zwar (als Ort der Unterrichtung) nicht ausdrücklich genannt ist, die jedoch von der Sache her auf einen engen Zusammenhang zu der Örtlichkeit und zum gewöhnlichen Lehrprogramm des Gymnasions schließen lassen.

In seiner Gliederung folgt der Beitrag der hellenistischen Dreiteilung des Lebensalters,

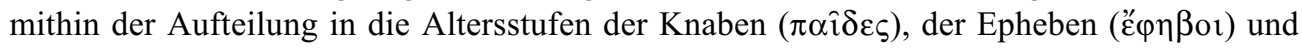
der jungen Bürger (véor).

\section{Der Elementarunterricht der Knaben (bis zur Ephebie)}

Im Alter von sieben Jahren begann der junge Grieche für gewöhnlich mit dem Elementarunterricht. Dieser mußte nicht notwendigerweise in einer öffentlichen Institution abgehalten werden, konnte aber, wie es in einigen Fällen belegt ist, durchaus räumlich und institutionell an ein Gymnasion angeschlossen sein. Nach populärer Auffassung setzte mit diesem Schritt für die Knaben $(\pi \alpha \hat{\imath} \delta \varepsilon \varsigma)$ die Härte und Mühsal des Lebens ein: An die Stelle der elterlichen Obhut trat nun das gleichsam 'tyrannische' Regiment der Erzieher, Schreib- und Turnlehrer

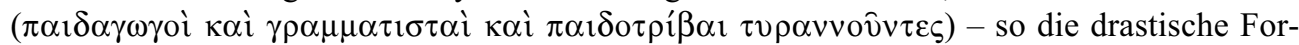
mulierng des Autors des pseudoplatonischen Axiochos. ${ }^{5} \mathrm{Da}$ diese Übertragung der Erziehungsaufgabe an Lehrer der allgemeinen Erziehungspraxis in den griechischen Städten entsprach - abgesehen von den auch auf diesem Gebiet besonderen Verhältnissen in Sparta -, bezeugt Xenophon im Staat der Lakedaimonier $(2,1)$, wenn er sagt: „Bei den anderen Griechen geben die, welche behaupten, ihre Söhne am besten zu erziehen, diese in die Obhut von Dienern, $\pi \alpha 1 \delta \alpha \gamma \omega \gamma o i ́$, sobald aber die Kinder verstehen können, was zu ihnen gesagt

5 Plat. Axioch. $366 \mathrm{~d}-367$ a 3. Vgl. hiermit das parallele Zeugnis von Teles V 50, 3-7 Hense: દỉ $\delta$ ' $\dot{\varepsilon} \kappa \pi \dot{\varepsilon}-$

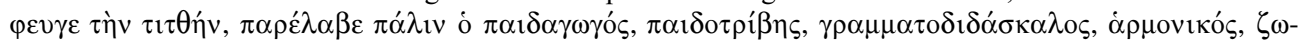

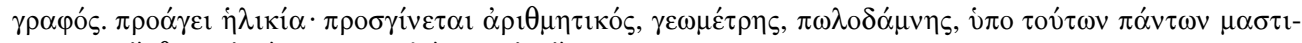

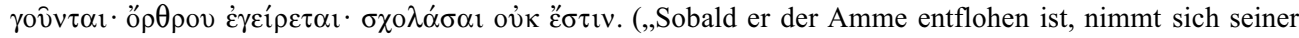
der Pädagoge, der Turn- und Elementarlehrer, der Musik- und Zeichenlehrer. Die Jugendzeit schreitet weiter voran: Es kommt dann der Arithmetiker, der Geometer und ... - von all diesen wird er gezüchtigt ... An Muße ist (auch danach) nicht zu denken“). Zur traditionellen Dreiteilung der Erziehung ( $\gamma \rho \alpha \mu \mu \alpha \tau \iota \sigma \tau \iota^{\prime}$,

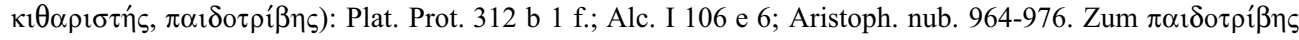
und der körperlichen Ausbildung: JÜTHNER: Philostratos, 3-8; MARROU: Erziehung, 181-204; KYLE: Athle-

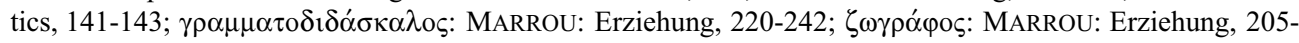

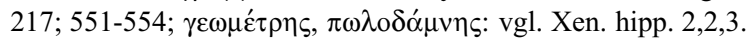


wird, schicken (sc. die Väter) sie sofort zu Lehrern, damit sie Lesen und Schreiben, die Musik und die Übungen in der Palaistra lernen“. ${ }^{6}$ Dabei läßt sich leider nicht genau bestimmen, welche Rolle die $\gamma \rho \alpha ́ \alpha \mu \alpha \tau \alpha$ im Vergleich zu den gymnastischen, militärischen und musischen Übungen spielten, ${ }^{7}$ da in den epigraphischen Zeugnissen die Lehrer verschiedenster Disziplinen als $\delta \imath \delta \alpha ́ \sigma \kappa \alpha \lambda$ o oder $\pi \alpha \imath \delta \varepsilon v \tau \alpha i ́$ bezeichnet und dementsprechend auch die verschiedenen im Gymnasion betriebenen Unterrichtsarten nur unter der Sammelbezeichnung $\pi \alpha i ́ \delta \varepsilon v \sigma i \varsigma, \pi \alpha 1 \delta \varepsilon i ́ \alpha$ oder $\delta 1 \delta \alpha \sigma \kappa \alpha \lambda i ́ \alpha$ zusammengefaßt werden. ${ }^{8}$ Darüber hinaus wurde die Bedeutung der drei Bereiche des Lernens in den einzelnen Städten unterschiedlich bewertet und entsprechend unterschiedlich in der Erziehungspraxis gewichtet.

Was die intellektuelle Erziehung betraf, so gliederte sich der Unterricht der $\pi \alpha \hat{\imath} \delta \varepsilon \varsigma$ bis zum Eintritt in die Ephebie in zwei Altersstufen: ${ }^{9}$ Bei den $\gamma \rho \alpha \mu \mu \alpha \tau o \delta$ i $\delta \alpha \sigma \sigma \kappa \alpha \lambda$ or oder auch $\gamma \rho \alpha \mu \mu \alpha \tau \imath \sigma \tau \alpha i ́$ lernten die jüngeren Knaben $(\pi \alpha \hat{\imath} \delta \varepsilon \varsigma)$ das Lesen und Schreiben. ${ }^{10}$ Im Alter

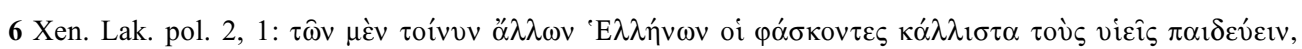

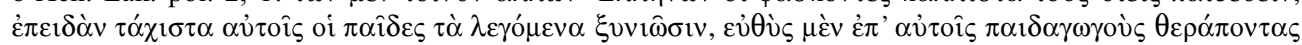

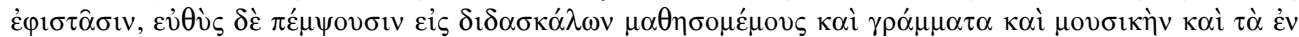
$\pi \alpha \lambda \alpha i \sigma \tau \rho \alpha$. Zur Stelle: ReBeniCh: Xen. Lak. pol., 93 A. 17 f.; OllieR: Xen. Lak. pol., 25 f. Xenophon spielt auf die unterschiedlichen Erziehungsarten an: Der freiheitlichen, privat vermittelten und getragenen athenischen Erziehung wird die staatliche, auf Disziplin ausgerichtete Spartas entgegengestellt. Vgl. die ausführliche Beschreibung der athenischen Erziehung bei: Plat. Prot. 325 c $5-326$ e 1 .

7 In Athen scheint nach Aussage des Protagoras (Plat. Prot. 325 d 7 - e 1) das vordringliche Erziehungsziel

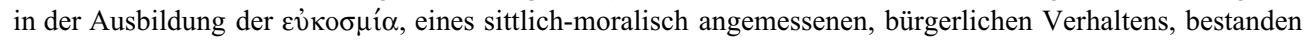

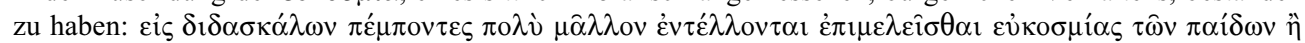

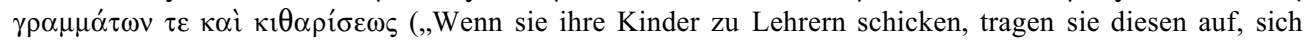
weitaus stärker um die Sittsamkeit von jenen zu kümmern, als für um Lesen, Schreiben oder das Kitharaspiel“). Diesem ethischen Zweck dient auch die dem Elementarunterricht angeschlossene Dichterlektüre sowie die Unterrichtung in den musischen und gymnischen Disziplinen (325 e $1-326$ c 3). Siehe hierzu ausführlich: BERND MANUWALD: Platon Werke VI 2. Protagoras. Übersetzung und Kommentar, Göttingen 1999, 217-222.

8 Siehe etwa I. Delos 1503 (der Demos der auf Delos lebenden Athener ehrt Theodoros, Sohn des Aristion,

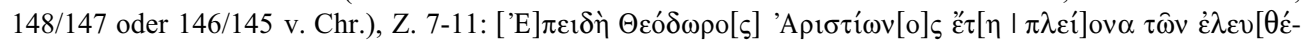

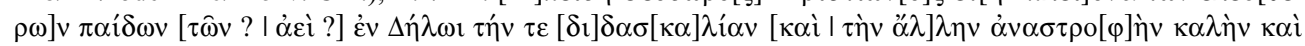

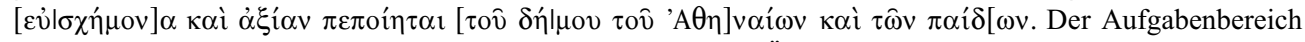

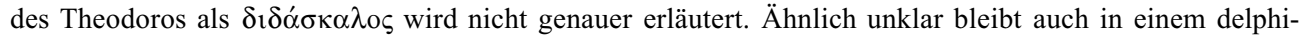
schen Proxeniedekret (um 134 v. Chr.) die langjährige Tätigkeit des Androtimos, Sohn des Dexion, aus Karyne, die als $\delta i \delta \alpha \sigma \kappa \alpha \lambda i \alpha \tau \hat{\prime} v \pi_{\alpha i ́} \delta \omega v$ (Z. 4) bezeichnet wird: FD III 3, 119. Siehe auch I. Oropos 370

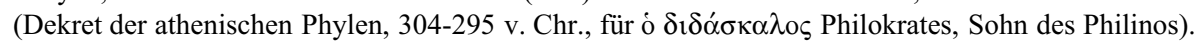

9 Diese Zweiteilung der 'Knabenzeit' in $\pi \alpha \hat{\imath} \delta \varepsilon \varsigma$ und $\mu \varepsilon \imath \rho \alpha ́$ kı $\alpha$ liegt auch den Bemerkungen des Teles (5,50,3-7 HENSE) zugrunde, wenn er seinen Zuhörern zu erweisen sucht, daß das Leben mehr leidvolle als

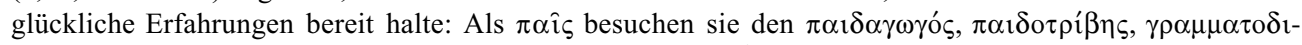

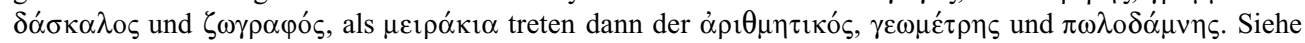
hierzu die Bemerkungen von FuENTES GonZÁLEZ: Télès, $461 \mathrm{f}$. Zu diesem zweiten Teil der Ausbildung: MARROU: Erziehung, 243-279.

10 Zuerst lernten sie die Namen der Buchstaben, dann das Schreiben der Buchstaben, dabei wurde das Alphabet vorwärts wie rückwärts geübt, dann kamen die Silben an die Reihe, zunächst das Lesen und Schreiben von Silben, danach wurden erste Worte geübt, zuerst einsilbige, dann mehrsilbige. Es schlossen sich Deklinier- und Konjugierübungen an, schließlich wurden aus einzelnen Wörtern erste Sätze gebildet. Für die ersten Satzbildungen dienten dabei im allgemeinen philosophische $\chi \rho \varepsilon \hat{\imath} \alpha \iota$ und $\gamma v \omega \hat{\omega} \mu \alpha \iota$ zur Übung, aber auch leichte Passagen aus der griechischen Dichtung. $\mathrm{Zu}$ diesen Schreibübungen siehe jetzt ausführlich: CRIBIORE: Writing, 139-152; vgl. MARROU: Erziehung, 288-292; NILSSON: Schule, 11-15. 
von etwa zwölf Jahren begaben sich die älteren Knaben ( $\mu \varepsilon \iota \rho \alpha ́$ кı $\alpha$ ) dann in den Unterricht

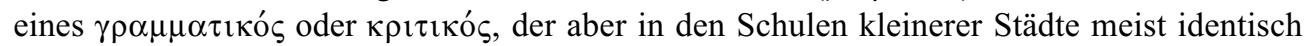
mit dem Elementarlehrer gewesen sein dürfte. In dieser Erziehungsphase wurden die Knaben zu vertiefter Lektüre epischer und lyrischer Dichtung angehalten und in die Kunst der Rezitation eingeführt. ${ }^{11}$

Wo aber wurde der Elementarunterricht abgehalten? Einen festen institutionellen Ort für den Unterricht der Knaben gab es nicht. In kleineren Städten konnte dieser durchaus in der Palästra des einzigen öffentlichen Gymnasions vor Ort stattfinden, ${ }^{12}$ in größeren Städten hingegen standen zahlreiche private Palästren, die entweder nach dem Besitzer ( $\pi \alpha 1-$

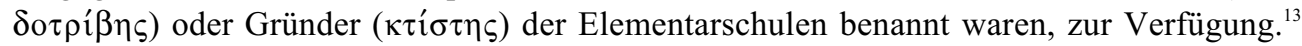
Oft begnügte man sich damit, auf einigen Steinen am Straßenrand zu lehren und zu lernen. ${ }^{14}$ Denn von wem und wo die Kinder unterrichtet wurden, lag für gewöhnlich in der Hand der Eltern, die den Unterricht eigenständig organisieren und finanzieren mußten. ${ }^{15}$ Die Bürger-

$11 \mathrm{Im}$ Protagoras (325 e 2 - 326 a 3) heißt es, daß im Anschluß an das Erlernen von Lesen und Schreiben

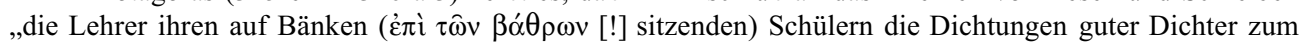
Lesen geben und sie zwingen, diese auswendig zu lernen - (Dichtungen), die viele Lebensregeln, viel Lob und Preis vortrefflicher Männer aus alter Zeit enthalten, damit das Kind diesen tüchtig nacheifere und danach strebe, auch solch ein Held zu werden“. Isokrates zufolge (2,43; vgl. Aischin. or. 3,135 f.) waren es vor allem Homer, Hesiod, Theognis, Epicharm und Phokylides, die auswendig gelernt werden mußten, wenn nicht gänzlich, so doch zumindest in Auswahl anhand von Florilegiensammlungen. Da die Schüler über keine eigenen Texte verfügten, diktierte der Lehrer oder gab ihnen kalligraphisch vorgeschriebene Texte, die sie abschreiben mußten, so daß im Laufe der Zeit eine kleine Sammlung berühmter Gnomen, homerischer Geschichten und kanonischer Gedichte gewissermaßen als Schulheft und Lesebuch zugleich zusammenkam. Im Anschluß daran wurden - vornehmlich anhand der homerischen Gedichte - die einzelnen Elemente der Grammatik erklärt und die Schüler dazu angehalten, zunächst Chrien, dann Paraphrasen der gelesenen Werke, schließlich Briefe, freie Erzählungen und Reden eigenständig abzufassen. Siehe hierzu neuerdings umfassend: MORGAN: Literate Education, 90-189; vgl. MARROU: Erziehung, 292-333.

12 Belege siehe Anm. 18-22; 25. Diese weisen m.E. darauf hin, daß es zumindest in einigen Städten üblich war, daß bereits paides regelmäßig das Gymnasion zu Unterrichtszwecken besuchten. Diese Altersstufe wurde in den Dekreten begrifflich von den übrigen Altersgruppen unterschieden und im Gymnasionsalltag sorgsam von den Epheben und neoi getrennt gehalten. Damit wende ich mich gegen die Ansicht von: GAUTHIER, Stadtbild und Bürgerbild, $4 \mathrm{f}$., dem etwa Walter Ameling in seinem Beitrag in diesem Band folgt. 13 ZiebARTH: Schulwesen, 33-37 (mit Belegen, dazu: BCH 36, 1912, 426. Nr. 20). Plat. Hp. Ma. 286 b 5 f.

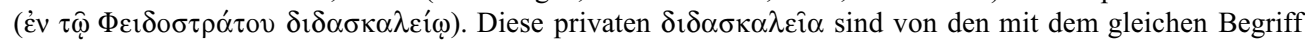
bezeichneten 'Unterrichtsräumen' in den öffentlichen Gymnasien auseinanderzuhalten (etwa Aischin. Tim. 1,9 f.), die wiederum von den 'Aufenthaltsräumen für Pädagogen' ( $\pi \alpha \imath \delta \alpha \gamma \omega \gamma \varepsilon \hat{\imath} \alpha$ : etwa IG XI 2, 199 A 104 f.; 112 f. [Delos, 3. Jh. v. Chr.]) zu unterscheiden sind; vgl. hierzu: HERRMANN WANKEL: Demosthenes. Rede für Ktesiphon über den Kranz II, Heidelberg 1976, 1132. Zu Elementarschulen im klassischen Athen siehe allgemein: MORGAN: Literate Education, 9-21.

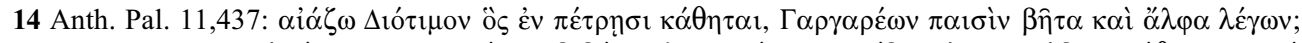

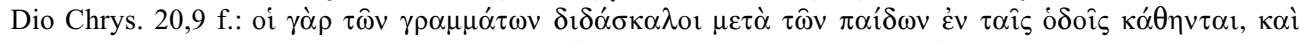

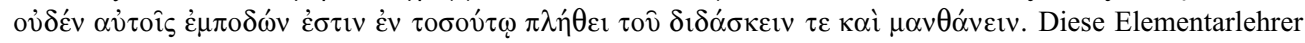
werden in den Papyri - freilich erst ab dem 3. Jh. n. Chr. - entsprechend spöttisch als $\chi \alpha \mu \alpha 1 \delta 1 \delta \alpha ́ \sigma \kappa \alpha \lambda o 1$ bezeichnet, siehe hierzu allgemein: CRIBIORE: Writing, 17-19.

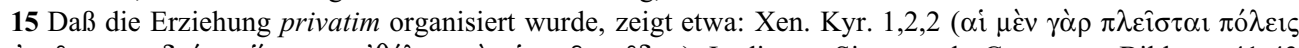

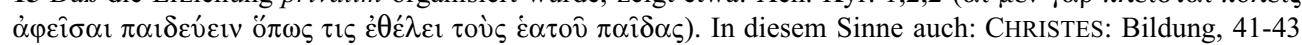
(im Anschluß an: ERICH ZIEBARTH, RE II A, 1921, 758-768, s.v. "Schulen", hier 758 f.; NiLSSON: Schule, 3). Der Elementarunterricht scheint in der Regel auch für ärmere Bürger erschwinglich gewesen zu sein, wie 
schaften mischten sich in die Erziehung der Jugend im allgemeinen nur insoweit ein, als sie die äußeren Rahmenbedingungen festlegten. So waren etwa in Athen durch ein angeblich

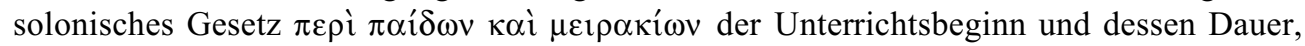
die Klassenstärke, die Altersstufen und Regeln der Schulaufsicht genau bestimmt. Dahinter stand offenkundig die Absicht, die guten Sitten aufrechtzuerhalten und sexuelle Übergriffe seitens älterer Bürger auszuschließen. ${ }^{16}$

Die Notwendigkeit, Lesen und Schreiben, also $\tau \dot{\alpha} \gamma \rho \alpha ́ \mu \mu \alpha \tau \alpha$, zu erlernen, wurde schon früh erkannt, und manifestierte sich in von philosophischer Seite erhobenen Forderungen nach allgemeiner Schulpflicht und öffentlicher Finanzierung. ${ }^{17}$ Allerdings wurden diese allem Anschein nach nur in wenigen Städten auch in die Tat umgesetzt: ${ }^{18}$ Aus hellenistischer Zeit sind bislang überhaupt nur vier Stiftungen reicher großzügiger Bürger und spendenfreudiger Könige bekannt, die allen freigeborenen Kindern den Besuch des Elementarunterrichts im Gymnasion ermöglichten - es sind dies die berühmten Stiftungen des Eudemos in Milet und des Polythrus in Teos sowie die der pergamenischen Könige in Delphi und Rhodos. ${ }^{19}$ Angesichts dieser geringen Zahl bezeugter Stiftungen kommt man nicht umhin festzustellen, daß derartige Initiativen zugunsten des öffentlichen Elementarunterrichts letztlich Ausnahmen und kurze Episoden blieben, die offenkundig nie lange Bestand hatten.

Darüber hinaus ist zu beachten, daß es sich in den wenigen überlieferten Fällen, in denen Gemeinden sich bereit erklärten, neben dem Kostgeld auch das Schulgeld für Flüchtlingskinder aus befreundeten oder stammesverwandten Gemeinden zu zahlen, um Notsituationen handelte, die solche finanziellen Hilfen nur für einen möglichst kurzen Zeitraum vorsahen. In dieser Weise unterstützten etwa die Troizener die attischen Flüchtlingskinder oder die Bewohner von Astypalaia die aus der Gefangenschaft befreiten ephesischen Kinder. ${ }^{20}$ Die

JOCHEN MARTIN: “Zur Stellung des Vaters in antiken Gesellschaften”, in: H. SÜSSMUTH (Hrsg.): Historische Anthropologie. Der Mensch in der Geschichte, Göttingen 1984, 103, hervorgehoben hat.

16 Aischin. Tim. 1,6-11. Die von Aischines erstellte Sammlung von Gesetzen bezieht sich dabei nicht speziell auf die Verhältnisse in Gymnasien, sondern wohl eher allgemein auf jegliche Art von Unterricht und Lehrern: ANDREW FORD: "Reading Homer from the Rostrum: Poems and Laws in Aeschines 'Against Timarchus"”, in: SimON GOLDHILl / ROBIN G. OSBORNE (Hgg.): Performance Culture and Athenian Democracy, Cambridge 1999, $42 \mathrm{f}$.

17 So sieht etwa Aristoteles für seinen besten Staat eine gesetzlich festgeschriebene gemeinsame Erziehung aller Bürger vor: Pol. 8, 1337 a 11-32.

18 Selbst die Existenz eines Paidonomos, eines städtischen Amtsträger, dem die allgemeine Aufsicht über die Erziehung der Kinder oblag, bedeutete nicht zwangsläufig, daß der Elementarunterricht in der betreffenden Stadt aus öffentlichen Geldern bestritten wurde. Zum Amt des paidonomos: OTTO SCHULthess, RE XVIII 2, 1942, 2387-2389, s.v. "paidonomoi".

19 Eudemos in Milet (200/199 v. Chr.): SIG $^{3}$ II 577 = ZIEBARTH: Schulwesen; Polythrous (um 200 v. Chr.): SIG $^{3}$ II 578; Delphi (160 v. Chr.): SIG II 672 = Schenkungen 94 [E]; Rhodos: Polyb. 31,31,1-3 = Schenkungen 212 [L]. S. hierzu die grundsätzlichen Bemerkungen von: HARRIS: Literacy, 146; WEBER: Dichtung, 154-164.

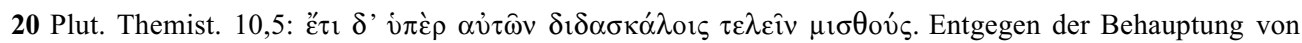
FRANK J. Frost: Plutarch's Themistocles. A Historical Commentary, Princeton N.J. 1980, 119 (im Anschluß an: MARROU: Erziehung, 72) stellt die Nachricht keine „evidence for early public education“ dar.

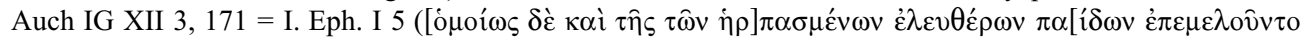

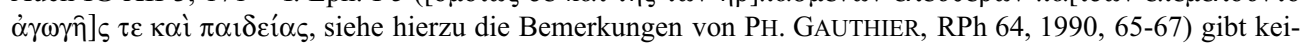
nen Hinweis auf eine öffentliche Bezahlung des Lehrers. Ein ähnliches Bild ergibt sich bei neuerlicher Musterung der ansonsten immer wieder in der Literatur angeführten Quellenbelege: (1) Hdt. 6,27: In Chios wer- 
beiden angeführten Fälle lassen darauf schließen, daß die private Schulfinanzierung gang und gäbe war, und die aufnehmenden Bürgerschaften über keine eigene, öffentlich finanzierte Lehrerschaft verfügten. ${ }^{21}$ Selbst wenn einige städtische Gesetze der hellenistischen Zeit die Väter dazu verpflichten suchten, ihren Söhnen zumindest eine elementare Bildung zukommen zu lassen, wie es etwa die hellenistische Literatur dem Gesetzeswerk des Charondas nachsagte, ${ }^{22}$ war ein öffentlich finanzierter Elementarunterricht keineswegs in jeder Stadt anzutreffen. Nach wie vor wurde die Erziehung als Privatangelegenheit betrachtet, so $\mathrm{da} ß$ es grundsätzlich keinerlei generelles Interesse in den Bürgerschaften gab, den Unterricht kontinuierlich zu pflegen und zu finanzieren. Die Übernahme dieser Aufgaben beschränkte sich zumeist auf euergetische Unternehmungen einzelner Bürger.

Die bekannteste und zugleich am frühesten bezeugte Stiftung zugunsten des öffentlichen

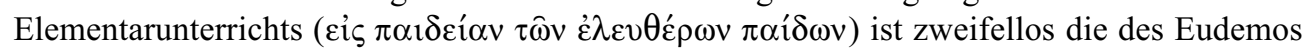
in Milet aus dem Jahr 206/205 v. Chr.: Nach dem Wunsch des Stifters sollten neben vier Turnlehrern vier weitere Elementarlehrer die Kinder „leiten und beaufsichtigen“ (') $\pi 1 \sigma \tau \alpha-$

den etwa 120 Kinder $(\pi \alpha \hat{\imath} \delta \varepsilon \varsigma)$ durch den Einsturz der Decke erschlagen; (2) Paus. 6,9,6: In Astypalaia werden rund 60 Kinder gemeinsam unterrichtet. Daß dies unter dem Dach eines öffentlichen Gebäudes geschah, sagt nichts über die Bezahlung der Lehrer; (3) Timaios FGrH 566 F 95 = Tzetz. chil. 4, 266: Akragas ist der Schauplatz einer legendenhaften Geschichte um den syrakusanischen Tyrannen Gelon, der nur durch eine göttliche Fügung als einziges Kind vor dem Tod bewahrt bleibt. Alle drei angeführten Stellen beziehen sich auf Einstürze öffentlicher Gebäude, in denen unterrichtet wurde. Das griechische Wort $\sigma \chi 0 \lambda \eta ́$ meint hierbei nur eine Unterrichtsstätte im allgemeinen Sinne, nicht eine feste, baulich gefaßte Bildungsinstitution, wie manche bildungshistorische Arbeit suggeriert.

21 So bereits: Christes: Bildung, 41 f. Auch I. Lampsakos 8 (3. Jh. v. Chr.) kann hierzu nicht als Beleg angeführt werden. Zwar werden in diesem Beschluß alle $\delta 1 \delta \alpha ́ \sigma \kappa \alpha \lambda o \imath$ und $\mu \alpha \theta \eta \tau \alpha i ́$, die sich in der Stadt zu Ausbildungszwecken aufhielten von der Kopfsteuer ( $\left.\sigma u ́ v \tau \alpha \xi_{1 \zeta}\right)$ befreit, doch kann das kaum als eine Maßnahme städtischer 'Kulturpolitik' gewertet werden. Die Maßnahme sollte wohl vielmehr bezwecken, die Zahl der Lehrer in der Stadt allgemein zu erhöhen. Diese wiederum betrieben dort entweder in einem öffentlichen Gymnasion eine private Schule oder bei wohlhabenden Familien. Auch das Grabmal des sogenannten

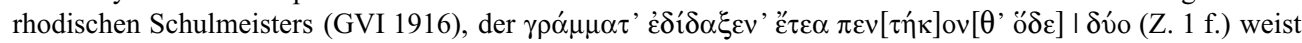
auf die private Finanzierung des Elementarunterrichts hin, da das Grab bezeichnenderweise nicht von der Bürgerschaft, sondern offenkundig von Schülern errichtet wurde, die sich dankbar ihrer eigenen Schulzeit (und womöglich die ihrer Kinder und Enkel angesichts des langen Lehrerdaseins des Unbekannten) erinnerten. Siehe etwa die Grabstele des Dorotheos, Sohn des Pelopidas (I. Oropos 584, 1. Jh. v. oder 1. Jh. n. Chr:

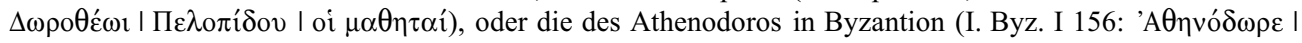

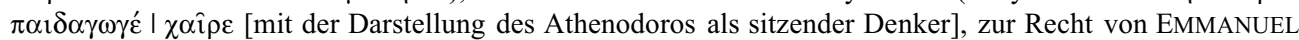
VOUTIRAS, EA 30, 1998, 145-147 in das 2. Jh. v. Chr. gesetzt, da das Relief den in dieser Zeit verbreiteten Denkertypus aufgreift, vgl. etwa PFUHL / MöBIUs: Grabreliefs II 841; 844).

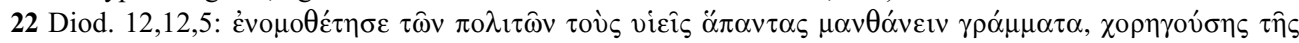

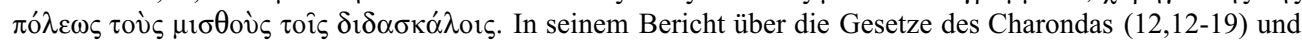

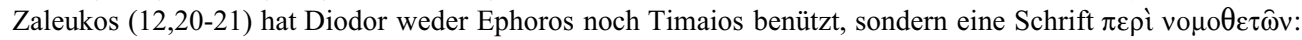
Klaus MeISTER: Die sizilische Geschichte bei Diodor. Von den Anfängen bis zum Tod des Agathokles. Quellenuntersuchungen zu Buch IV-XXI, Diss. München 1967, 54. Tatsächlich mag das Gesetz den Gesetzen von Thurioi entnommen sein. Diese hatte bekanntlich Protagoras erstellt, der als Sophist schon von seiner Profession her im besonderen $\mathrm{Ma} ß$ an der Förderung von Literalität und intellektueller Bildung Interesse hatte. Träfe diese ansprechende Vermutung von MAX MÜHL ("Die Gesetze des Zaleukos und Charondas II", Klio 22, 1929, 440 f.) zu, so wäre diese staatliche Förderung in Thurioi freilich als Ausnahmefall anzusehen. ZIEBARTH: Schulwesen, 32 bestreitet aus diesem Grund die Historizität der Gesetze, wogegen CHRISTES: Bildung, $41 \mathrm{f}$. an dieser festhält. 
$\tau \varepsilon \hat{\imath} v){ }^{23}$ Alle Männer, die sich für diese Aufgabe geeignet hielten, mußten ihre Kandidatur zwei Wochen vor der Wahl beim $\pi \alpha 1 \delta o v o ́ \mu \varsigma$ des nächsten Jahres melden, also bei demjenigen Beamten, dem im darauffolgenden Jahr die allgemeine Aufsicht über die Lehrer der Knaben oblag. In der Volksversammlung, die über die Wahl der Lehrer entschied, mußten die Kandidaten dann unter Eid versichern, daß sie in keiner Weise zuvor versucht hätten, die Wahl zu manipulieren. Die Eidesformel deutet darauf hin, daß die Lehrer- und Turnmeisterstellen recht begehrt gewesen sein müssen, da sie den Inhabern kein üppiges, aber immerhin ein regelmäßiges Dauereinkommen sicherten. Die fachlichen Fähigkeiten der Lehrer wurden erstmals nach Ablauf des ersten Unterrichtsjahres überprüft: Wie für mehrere Städte bezeugt ist, mußten sich die Lehrer alljährlich einer öffentlichen Prüfung unterziehen, einer $\alpha$ đo $\delta \varepsilon i ́-$ $\xi_{1 \varsigma} \delta 1 \delta \alpha \sigma \kappa \alpha ́ \lambda \omega v$ - so die offizielle Bezeichnung des 'Lehrer-Schaulaufens' in Kos. ${ }^{24}$

Diese Prüfungen der Lehrer waren - schon aus praktischen Gründen - mit den Prüfungen der Schüler verknüpft und erfolgten in Form von öffentlichen Wettbewerben in verschiedenen Unterrichtsgegenständen. Nach Ausweis der gleichfalls in die Zeit um 200 v. Chr. zu datierenden Polythrus-Inschrift fanden in Teos die Prüfungsdarbietungen aus dem Bereich des Elementar- und Musikunterrichts, „die früher (ausschließlich) im Gymnasion abgehalten worden waren“, nun im Rathaus und für den Turnunterricht im Gymnasion statt. ${ }^{25}$ In Priene gehörte es dabei zu den Pflichten eines $\pi \alpha \imath \delta$ ovó $\mu$ o , ,die Prüfungen in den

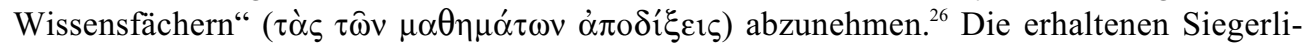
sten aus Teos und anderen Städten zeigen für die Altersstufe der Kinder ( $\pi \alpha \hat{\imath} \delta \varepsilon \varsigma$ ) ein breites Spektrum an Wettbewerben, die dem Bereich der intellektuellen Bildung im weitesten Sinne zugeordnet werden können. So gab es Agone in Kalligraphie und Lesen, im monologischen oder auch dialogischen Deklamieren von Stellen aus Dichtung, Komödie und Tragödie, doch auch in Arithmetik und schließlich - leider unspezifiziert - in sogenannten 'Wissensfächern' oder auch in der Polymathie bzw. Philomathie, ${ }^{27}$ d.h. in einer Probe des damaligen

23 Ähnlich die Polythrus-Inschrift in Teos ( $\mathrm{SIG}^{3}$ II 578, Z. 8-10), wo drei Lehrer für den sprachlichen Ele-

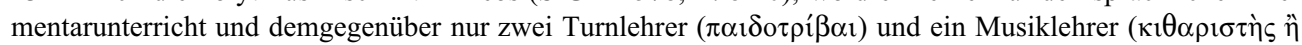

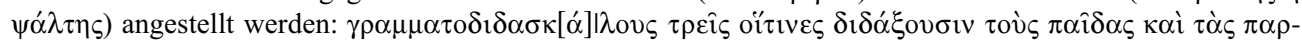

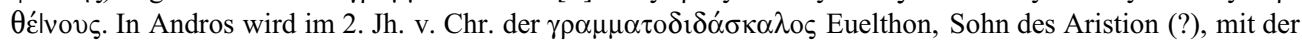
Verleihung der Proxenie geehrt: IG XII Suppl. 248. Zu den Funktionen des Paidotriben: JULIUS JÜTHNER, RE XVIII 2, 1942, 2389-2396, s.v. "paidotribes"; DECKER: Sport, 143-150; 176 f. (mit neuerer Literatur).

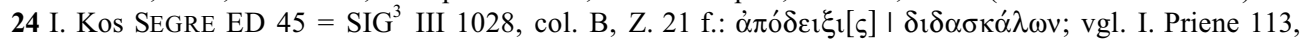

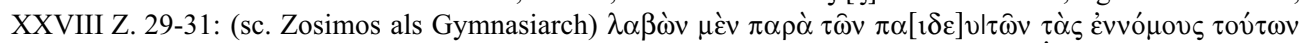

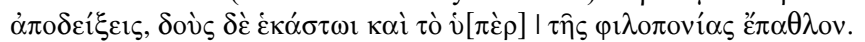

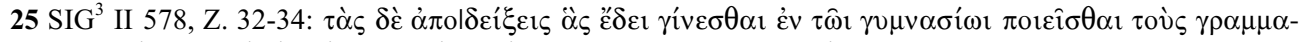

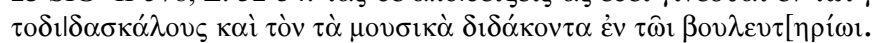

26 I. Priene 114 (nach 84 v. Chr.), XXXII Z. 20 - XXXIII 21 (mit der Verbesserung von Hermann Diels in

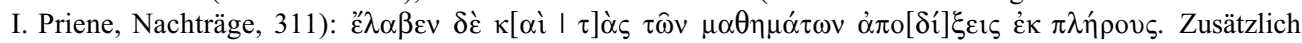
wurde von einem Paidonomen erwartet, Siegespreise für Lehrer wie Schüler zu spenden, wie es gleichfalls für Zosimos in Priene bezeugt ist (nach 84 v. Chr.): Er spendete „Wettkampfpreise für die mit der Philologie verbundenen Wissensgebiete und für die gymnische Betätigung“" und erwies sich damit ein weiteres Mal als ein verschwenderisch großzügiger Wohltäter der städtischen Jugend (I. Priene 113 [nach 84 v. Chr.],

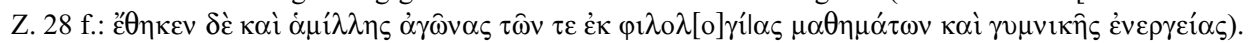

27 Der paidonomos Chrysippos stiftete in Mylasa (I. Mylasa II 909, Z. 18 f.) Preise für die Knabenwettbe-

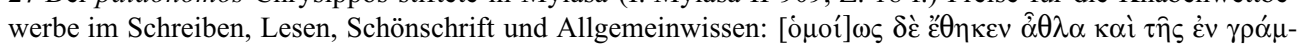

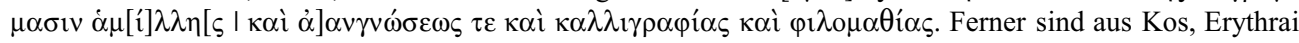
und Teos Sieger im Wettbewerb $\pi \mathrm{o} \lambda \nu \mu \alpha \theta i \alpha$ bekannt: I. Kos SEGRE EV 215 (Statuenweihung der Eltern, 
Allgemeinwissens von der Art, wie es uns etwa ein ägyptischer Papyrus aus dem 1. Jh. v. Chr. präsentiert. ${ }^{28}$

Etwa seit dem Beginn des 2. Jh. v. Chr. erfuhr die bis dahin nur äußerst sporadisch geförderte Schulung des Intellekts der Knaben zumindest in einigen Gymnasien eine gelegentliche Ergänzung durch Lehrkräfte, die die Gymnasiarchen zusätzlich auf eigene Kosten für eine gewisse Zeit während ihrer Amtsführung anstellten. ${ }^{29}$ So bezahlte etwa in Eretria der Gymnasiarch Elpinikos (um 100 v. Chr.) aus eigenen Mitteln einen Rhetor und einen Fechtmeister, „die im Gymnasion für die Knaben, Epheben und für alle übrigen, die von derartigen Dingen einen Nutzen empfangen wollten, Unterricht abhielten“. ${ }^{30}$ Aus dem zuletzt angeführten Dekret wird deutlich, daß, auch wenn uns insgesamt bislang nur vergleichweise wenige Zeugnisse vorliegen, immerhin das Ziel der intellektuellen Ausbildung der paides im Laufe der hellenistischen Zeit erheblich erweitert worden war: Laut Aristoteles war das Lesen und Schreiben im 4. Jh. v. Chr. zwar wegen der „Nützlichkeit für das Leben“ und

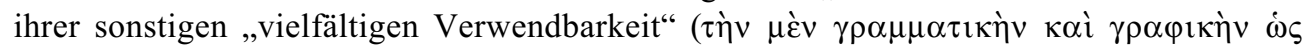

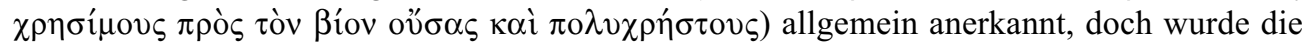
bloße Vermittlung der Literalität bereits als hinreichend angesehen. Insbesondere die zuletzt genannten Zeugnisse weisen darauf hin, daß in hellenistischer Zeit - wenigstens in manchen Gymnasien - sich die Knaben darüber hinaus nun auch eine Art 'Bildungswissen' erwerben sollten, wie es etwa in der Existenz von Agonen im 'Vielwissen' ( $\pi$ o $\lambda \nu \mu \alpha \theta i ́ \alpha)$ oder 'Wissenseifer' ( $\left.\varphi \imath \lambda_{\mathrm{o}} \mu \alpha \theta^{\prime} \alpha\right)$ zum Ausdruck kommt. Ein solcher Bildungsdrang sagte man, abge-

1. Jh. v. Chr.; I. Erythrai 81 (Siegerliste von Knaben und Epheben, um 100 v. Chr.), Z. 4; CIG 3088, wo

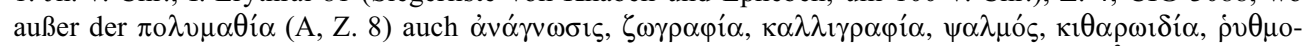
$\gamma \rho \alpha \varphi_{i}^{\prime} \alpha, \kappa \omega \mu \omega \imath \delta i ́ \alpha, \mu \varepsilon \lambda \sigma \gamma \rho \alpha \varphi i ́ \alpha$ erwähnt sind. Vgl. auch eine Siegerliste aus Chios ( SIG $^{3}$ III 959, 2. Jh.

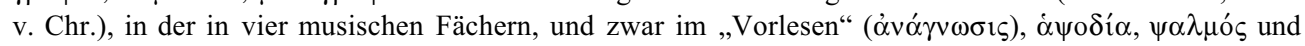
$\kappa \imath \theta \alpha \rho \imath \sigma \mu o ́ \varsigma$, die Sieger bei den Knaben genannt werden, Fragmente zweier Kataloge von siegreichen $\pi \alpha \rho-$

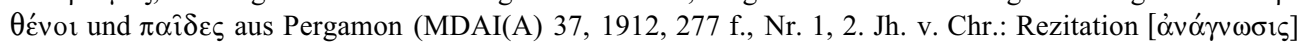
von epischer, elegischer und lyrischer Dichtung; HEPDING, MDAI(A) 35, 1910, 436, Nr. 20, undatiert: $\kappa \alpha \lambda$ $\lambda_{1 \gamma \rho \alpha \varphi i ́ \alpha)}$ nennt, sowie eine Siegerliste bei den Knaben aus Magnesia am Mäander ( SIG $^{3}$ III 960, freilich

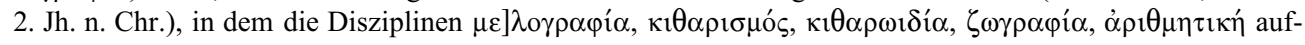
geführt werden.

28 HeRMANN DiELS: "Laterculi Alexandrini. Aus einem Papyrus ptolemaeischer Zeit", SBAW 1904.2, 1-16 $=$ P. Berol. inv. 13044 recto $=\mathrm{P}^{2} 2068=$ CRIBIORE: Writing, 270, Nr. 380. In den einzelnen Rubriken des wohl aus dem 1. Jh. v. Chr. stammenden Papyrus werden berühmte Gesetzgeber, Bildhauer, Architekten, Ingenieure, Bauwerke, Berge, Flüsse, Quellen und Häfen aufgelistet. Weitere Beispiele solcher 'Schulhefte': CRIBIORE: Writing, 269-284, Nr. 379-412.

29 Das fügt sich gut in das Bild ein, was wir aus der eingangs angeführten Passage im pseudoplatonischen Dialog Axiochos (366 e 1-3) von der intellektuellen Unterrichtung der paides erfahren. Die Zweistufigkeit

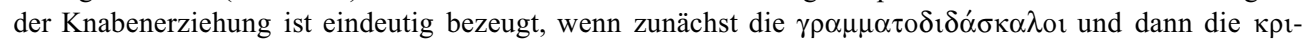

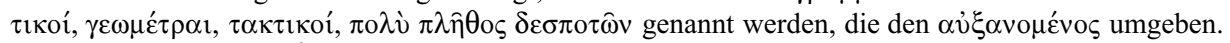

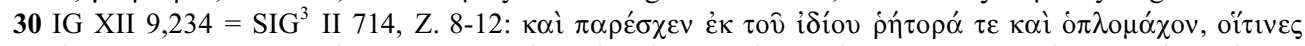

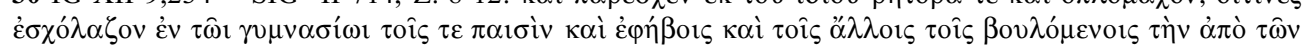
$\tau$ oiov́ $\tau \omega v \dot{\omega} \varphi \varepsilon \lambda i \alpha v \dot{\varepsilon} \pi \imath \delta \dot{z} \chi \varepsilon \sigma \theta \alpha$. Siehe auch den Kommentar von: RiCHARDSON / HEERMANCE, AJA 11, 1896, 181, der in der Anstellung eines Rhetors bzw. eines Homer-Philologen einen Hinweis darauf sieht, daß es einen festen Bestand an Gymnasionslehrern gab, der gegebenfalls, soweit es erforderlich erschien, von den amtierenden Gymnasiarchen aus eigenen Mitteln ergänzt wurde. Alle drei Altersstufen scheint auch der mit der Verleihung der Proxenie in Delphi geehrte Apollonios, Sohn des Dionysios, aus Aigeira (1. Jh.

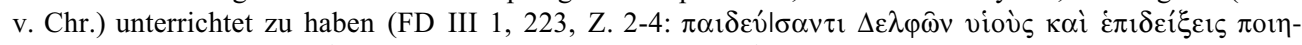

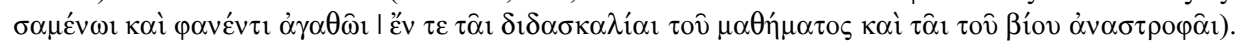


sehen von einem allgemein 'diszipliniertem Verhalten' ( $\left.\varepsilon \dot{\tau} \tau \alpha \xi^{\prime} \alpha\right)$ und der 'Elternliebe' ( $\varphi$ -

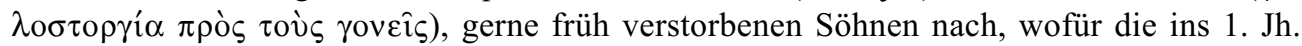
v. Chr. fallende Ehrung des Obrimos aus Iasos als Beispiel dienen kann. ${ }^{31}$ Es hat so den Anschein, als ob seit etwa der Mitte des 2. Jh. v. Chr. der Kanon der körperlichen, charakterlichen und sozialen Qualitäten des Jugendlichen und jungen Bürgers offenkundig um die allgemeine 'Wißbegier' ( $\left.\varphi \imath \lambda_{o} \mu \alpha \theta i \alpha\right)$, also um das Streben nach möglichst umfassenden Kenntnissen auf den verschiedenen Gebieten des Wissens, erweitert wurde.

\section{Intellektuelle Bildung im Rahmen der Ephebie (epheboi)}

Mit dem Eintritt in den Kreis der Epheben begann für die jungen Athener nach Ansicht des kynischen Wanderpredigers Teles auch dieser Lebensabschnitt voller leidvoller Erfahrungen. So heißt es in dem kurzen Essay Darüber, daß Genuß nicht das Lebensziel ist: „Dann ist man Ephebe: Statt anderer hat man dann den Kosmeten, Turnlehrer, Waffenmeister und Gymnasiarchen zu fürchten - (denn) von all diesen wird man mit der Peitsche geschlagen, drangsaliert und geplagt““.32 Der Eintritt in die Ephebie brachte einschneidende Veränderungen mit sich: In Athen mußten die jungen Männer nun regelmäßig das Lykeion und die Akademie aufsuchen, wo sie eine vorwiegend sportliche und militärische Ausbildung erhielten. Anstelle der privaten Lehrmeister, die etwa den Knaben im Fechten Unterricht erteilten, unterstanden sie nunmehr gänzlich der Obhut und Aufsicht des Gymnasiarchen und seiner Helfer, der Kosmeten und Sophronisten. Die private Erziehung des Heranwachsenden mündete so mit der Ephebie im öffentlichen Wehrdienst, der in Athen allerdings nach dem Sturz des Demetrios von Phaleron auf ein Jahr begrenzt worden und seitdem auch nicht mehr verpflichtend war.

31 SEG 4, 1929, 220 = I. Iasos 120 (Statue des Knaben Obrimos, Sohn des Artemon, aus Iasos), Z. 3-5:

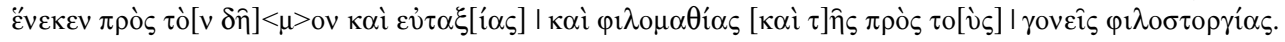

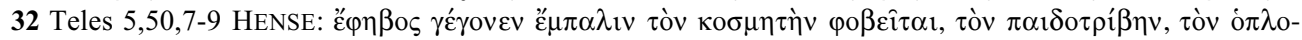

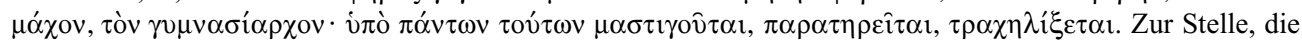
sich auf die athenischen Verhältnisse bezieht (siehe etwa die ausschließlich für Athen bezeugte Bezeichnung

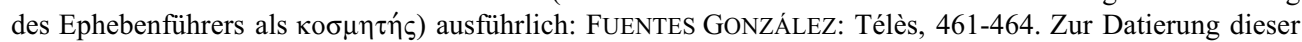

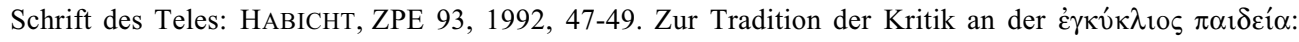
SCHOLZ: Philosoph und Politik, 60 mit A. 174-177 (Belege). Vgl. hiermit die bereits zur Erwähnung gekommenen Passage aus dem Axiochos (366 d - 367 a): „Ist der Knabe in die Liste der Epheben eingetragen, so tritt zwar die Aufsicht und die Einschüchterung (durch die Lehrer) stärker zurück, aber dann folgen das Lykeion und die Akademie, die Gymnasiarchie, deren Amtszepter und andere ungezählte Widerwärtigkeiten. So ist der Jüngling die ganze Zeit den Sophronisten und dem Gremium des die Jugend beaufsichtigen-

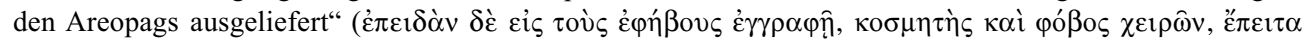

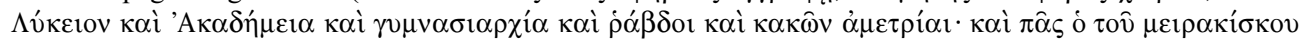

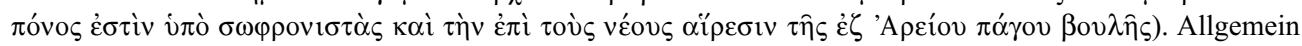
zur Aufsicht des Gymnasiarchen über die Besucher der Institution und Amtsgewalt: siehe unten den Beitrag von Christof Schuler in diesem Band. Zur athenischen Ephebie, aus der man nach Angabe des Teles (5,50,10 HENSE) mit zwanzig Jahren wieder ausschied, siehe unten den Beitrag von Leonhardt Burckhardt in diesem Band. 
Die athenische Ephebie erfuhr bekanntlich unter römischer Herrschaft nach den Reformen von 336/335 und 307 v. Chr. abermals eine grundlegende Änderung: Nach dem endgültigen Verlust der politischen und militärischen Unabhängigkeit scheint sich die Ephebie in ein exklusives, überaus kostspieliges Körper und Geist schulendes Bildungsinstitut verwandelt zu haben. ${ }^{33}$ Spätestens seit dieser Maßnahme wurden die Gymnasien endgültig zu den Heimstätten von Philosophen, Rhetoren und anderen Gelehrten. Der erste epigraphische Beleg für diese Neuausrichtung stammt aus einem Ehrendekret für die Epheben des Jahres 124/123 v. Chr., die unter anderem gewürdigt werden, weil ,sie das ganze Jahr über mit großer Ausdauer bei Zenodotos im Ptolemaion und Lykeion in die Schule gingen, ebenso aber auch bei anderen Philosophen und bei allen sonstigen (Gelehrten), die sich im Lykeion und in der Akademie (aufhielten) “. ${ }^{34}$ Die Stoa scheint zumindest unter der Leitung Zenodots die intellektuelle Ausbildung dominiert zu haben. Es war allerdings keine rein philosophische Ausbildung, da neben der Philosophie - zumindest im 1. Jh. v. Chr. - auch Dichtung und Rhetorik auf dem Programm standen, wie aus mehreren Dekreten zu Ehren der Epheben hervorgeht. ${ }^{35}$ In dieses Bild fügt sich gut ein, daß 117/116 v. Chr. zum ersten Mal ein athenischer Ephebenjahrgang nach dem Abschluß seiner Studien 100 Bücher für die im Ptolemaion untergebrachte Bibliothek spendete. Im Blick auf die späte Einrichtung von Bibliotheken in Gymnasien ist zu vermuten, daß auch diese Bibliothek erst in der Zeit zwischen 130 und 120 v. Chr. im Ptolemaion eingerichtet worden war. ${ }^{36}$

Im Gegensatz zu Athen blieb freilich der traditionell militärische Charakter der Ephebie in vielen anderen Städten auch im 2. und 1. Jh. v. Chr. erhalten, und nur wenige Gymnasiarchen fanden sich bereit, die Epheben neben den sportlichen und militärischen Übungen zumindest für eine kurze Zeit - auch in den Genuß eines intellektuellen Unterrichts kommen zu lassen. ${ }^{37}$ Das früheste diesbezügliche explizite Zeugnis scheint das Proxeniedekret für

33 Die militärische Ausbildung wurde erst in augusteischer Zeit aufgegeben. Siehe hierzu: Burckhardt in diesem Band.

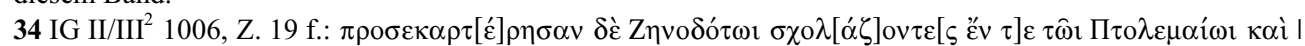

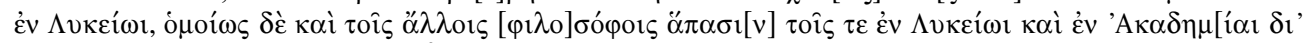

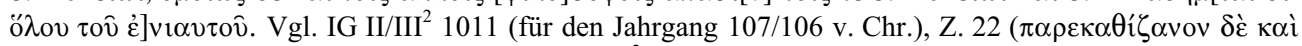

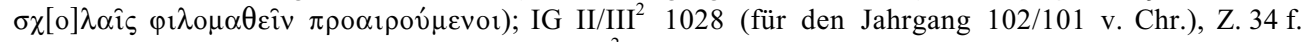

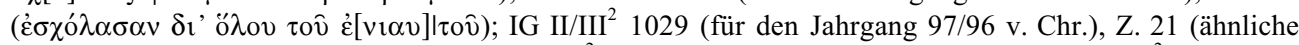
Formulierung wie vorhergehende Nr.); IG II/III ${ }^{2} 1030$ (nach 96/95 v. Chr.), Z. 29-31; IG II/III ${ }^{2} 1041$ (vermutlich für den Jahrgang 43/42 v. Chr.), Z. 10-12.

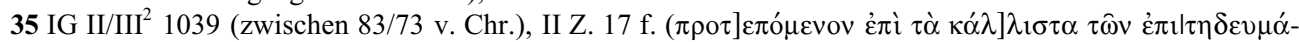

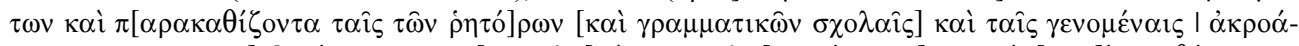

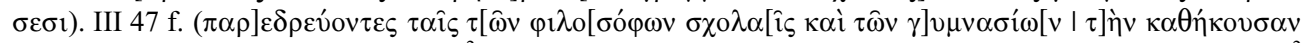

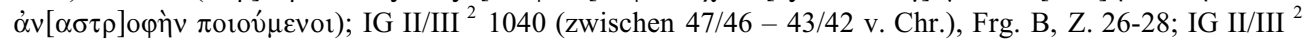

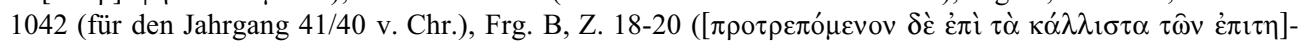

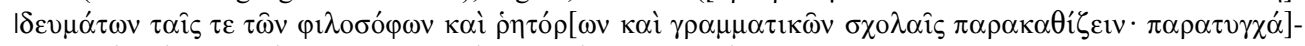

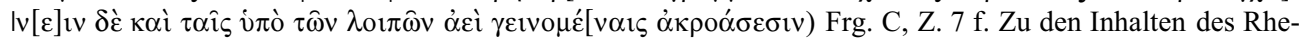
torenunterrichts siehe jetzt: MORGAN: Literate Education, 190-239. Zu den Geschichtskenntnissen eines Epheben des 2./1. Jh. v. Chr. siehe beispielsweise: I. Priene 316 (eine Liste der spartanischen Ephoren, die in den Türrahmen des Ephebeions eingeritzt wurde).

36 Belege siehe Anm. 88.

37 Der Vorrang der sportlichen und militärischen Übungen wird besonders anschaulich in einem pergamenischen Dekret zu Ehren eines unbekannten Gymnasiarchen (JACOBSTHAL, MDAI(A) 33, 1908, 375-379,

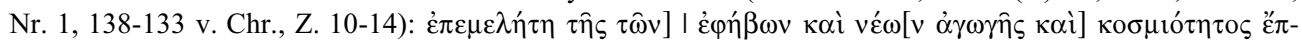


einen unbekannten Philosophen aus Makedonien zu sein, der im ersten Drittel des 2. Jh. v. Chr. im böotischen Haliartos nicht nur epideiktische Vorträge hielt, sondern auch im örtlichen „Gymnasion die Epheben unterrichtete und erzog““. ${ }^{38}$ In einem Ehrendekret aus Eretria aus der Zeit um 100 v. Chr. wird es dem Gymnasiarchen Mantidoros von der Bürgerschaft hoch angerechnet, daß er einen athenischen Homerphilologen finanzierte. Dieser offenbar sehr angesehene - Gelehrte war dazu verpflichtet, sowohl den Epheben, den neoi sowie nach Aussage der Inschrift allen Bürgern, „die sich der Paideia verbunden fühlten“, Unterricht im Gymnasion zu erteilen. ${ }^{39}$ In einem aus dem 1. Jh. v. Chr. stammenden Dekret einer unbekannten Stadt wird ein Wandergelehrter aus Thasos für seine Verdienste um die intellektuelle $\pi \alpha 1 \delta \varepsilon i ́ \alpha$ der Epheben und véor im allgemeinen wie im besonderen für seine öffentlichen Vorträge über die ruhmreiche Vergangenheit dieses Gemeinwesens geehrt. ${ }^{40}$ Desweiteren ist etwa aus Priene bekannt, daß der große Wohltäter Aemilius Zosimos (nach 84 v. Chr.) als Gymnasiarch der véor einen 'Grammatiker' anstellte, der eigens „die Epheben in allen mit der Philologie herrührenden Wissensgebieten anleiten sollte“. ${ }^{41}$ Intellektueller Eifer ( $\left.\varphi \imath \lambda_{\mathrm{o}} \mu \alpha \theta \theta^{\prime} \alpha\right)$ galt im 1. Jh. v. Chr. wenigstens in Teilen der Oberschicht durchaus als erstrebenswert, wie schließlich ein Dekret aus Iasos für den Ephebarchen Melanion be-

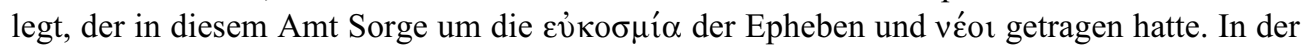
Begründung heißt es unter anderem: „Melanion ... hat sich im Gymnasion stets als jemand gezeigt, der keine Anstrengungen scheut, wißbegierig ist und sich stets dem Schönsten und Besten verschreibt, indem er sich sowohl in altergemäßen Erziehungsgegenständen ( $\pi \alpha_{l}$ -

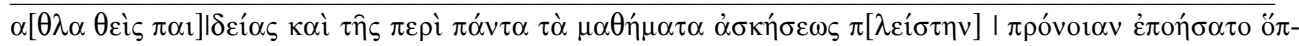

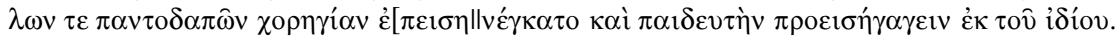

38 IG VII 2849 = SEG 44, 1994, 409 (mit den Änderungen von JOHN M. FOSSEY, Boeotia Antiqua IV, Amsterdam 1989, 35-39). Der Demos von Haliartos verleiht dem Philosophen [..]tes, Sohn des Xenokrates, aus Makedonien die Proxenie und andere Privilegien. Der Unterricht für die Epheben ist zwar aufgrund des Kontexts anzunehmen, freilich nur ergänzt. Immerhin ist mit einiger Wahrscheinlichkeit der Ort seines Wir-

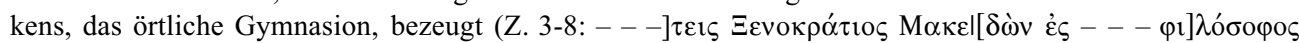

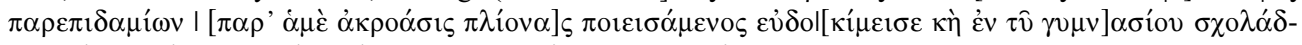

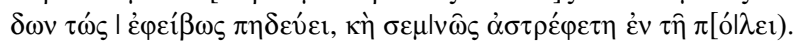

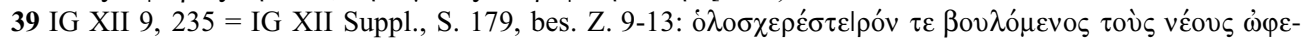

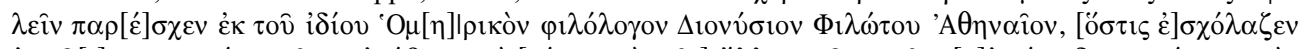

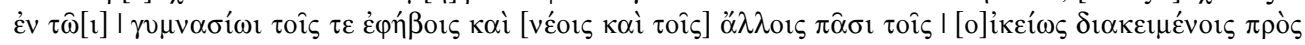
$\pi \alpha 1 \delta[\varepsilon i \alpha v$.

40 Christiane DunANT / JEAN POUiLloux: Recherches sur l'histoire et les cultes de Thasos de 196 av. J.-

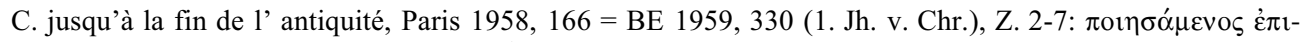

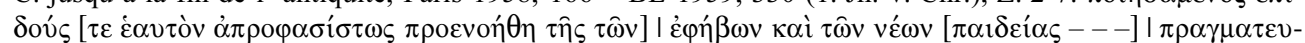

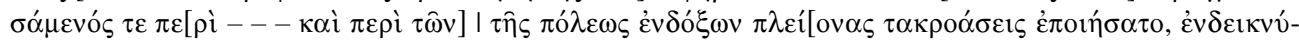

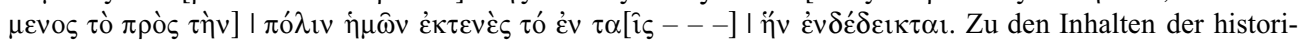
schen Unterrichtung siehe etwa das Inschriften-Graffiti im Türrahmen des Ephebeums von Priene (I. Priene 316 aus dem 2. oder 1. Jh. v. Chr.), das die spartanischen Ephoren auflistet.

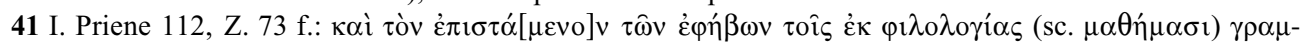
$\mu \alpha \tau$ «óv ... Darüber hinaus stiftete er zwei Hermen, die vor der Ephebenexedra Aufstellung finden sollten. Die Topos-Inschriften in Priene - eine weit verbreitete Unsitte, die Plutarch entsprechend geißelte (De curios. 520 e), - stammt nicht von den Knaben, sondern von den Epheben. Ähnliche Kritzeleien sind im Gymnasion der Neoi in Pergamon entdeckt worden (HePDING, MDAI(A) 32, 1907, 373, Nr. 135), darunter die

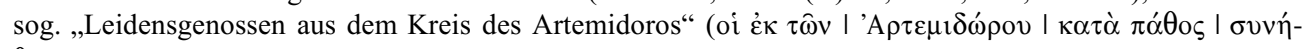
$\theta \omega v)$. Weitere Toposinschriften: HILLER VON GAERTRINGEN: Thera I, 176. 


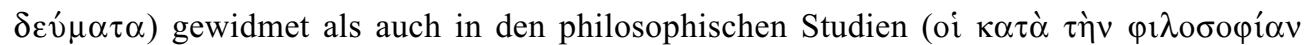

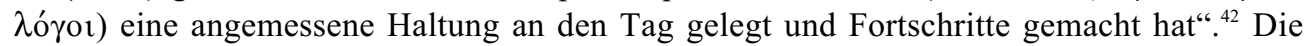
traditionelle Ausbildung im eigenen Elternhaus ist hier um den wohl in den Gymnasien der großen Städten empfangenen, philosophischen und nicht den praktisch orientierten rhetorischen Unterricht ergänzt. Der Hinweis auf seine philosophische paideia scheint für Melanion unerläßlich gewesen zu sein, um sich dem Kreis der 'Wissensbegierigen' ( $\varphi \imath \lambda_{0} \mu \alpha-$

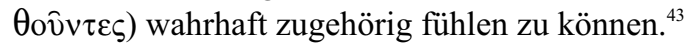

\section{Intellektuelle Bildung nach der Ephebie (neoi und pepaideumenoi)}

Der Perieget Herakleides erwähnt in seiner Schilderung Athens auch dessen Gymnasien. Akademie, Lykeion und Kynosarges, jedoch bemerkenswerterweise noch nicht das 229 gegründete Diogeneion, werden als annehmliche und beschauliche Orte geschildert, die, weil sie ,alle mit Bäumen bepflanzt und am Boden mit Rasenflächen versehen sind“, zum Müßiggang und Studium einladen. ${ }^{44}$ Das intellektuelle Angebot, das man in den drei genannten Gymnasien vorfand, wie „Faszination der Seelen durch Philosophen aller Art sowie Erholung, Kurse und Unterricht in Fülle“, machte nach Auffassung des Reiseschriftstellers neben den zahlreichen städtischen Festen ${ }^{45}$ das besondere Flair und die kulturelle Attraktivität der Stadt aus. Einen ähnlichen Ruf dürfte spätestens seit dem Beginn des 3. Jh. v. Chr.

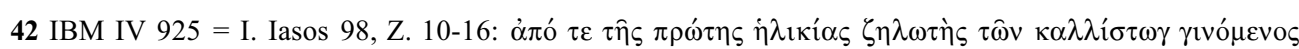

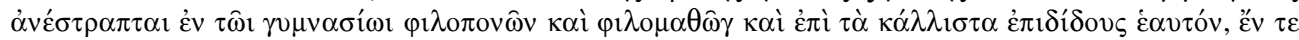

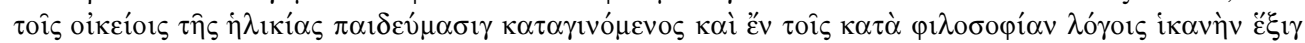

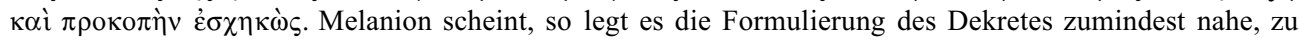
dem Zeitpunkt, als er das Amt bekleidete, selbst noch der Gruppe der véor angehört zu haben. Zum Amt des

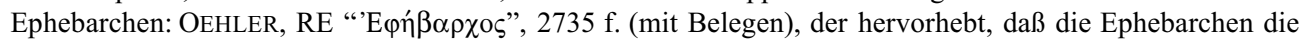
Gesamtaufsicht über die Epheben führten.

43 So werden auch im Dekret zu Ehren des Artemon, Sohn des Andron, aus Aphrodisias (ThÉOdORE REINACH: "Inscriptions d'Aphrodisias", REG 19, 1906, S. 79-150; 205-298, hier 117 f., Nr. 39, undatiert) neben den moralischen auch die intellektuellen Qualitäten des offenkundig jung Verstorbenen gerühmt (Z. 5-6:

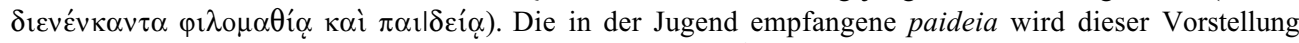

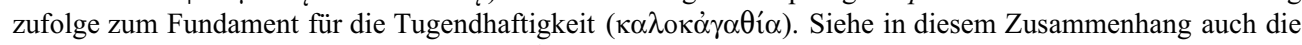
an dem Knaben Obrimos gerühmte $\varphi \imath \lambda \mathrm{o} \mu \alpha \theta i \alpha$ : Anm. 24 dieses Beitrags. Im Ehrendekret für den pergamenischen Gymnasiarchen Agias, Sohn des Agias, (JACOBSTHAL, MDAI(A) 33, 1908, 379-381, Nr. 2, vor 133 v. Chr., Z. 17-21) ist schließlich die Rede davon, daß dieser die Lehrer der Epheben ( $\pi \alpha 1 \delta \varepsilon v \tau \alpha i ́$ : nach der Verbesserung von HEPDING, MDAI(A) 35, 1910, 492 f.) mit Geschenken bedachte und es so erreichte, daß

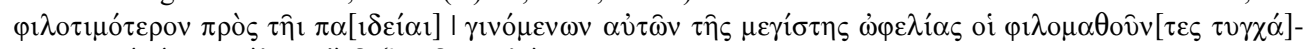

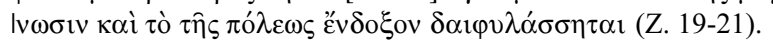

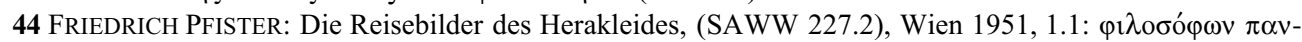

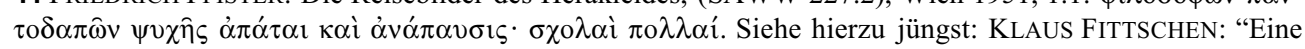
Stadt für Schaulustige und Müßiggänger. Athen im 3. und 2. Jh. v. Chr.”, in: WÖRRLE / ZANKER: Stadtbild und Bürgerbild, 55-60; 89; E. PERRIN: "Héracleides le Cretois à Athènes", REG 107, 1994, 192-202. Zu den vier genannten athenischen Gymnasien und allgemein zu ihrer kulturellen Funktion siehe ausführlich: WACKER: Gymnasion in Olympia, 131-137; 145-178.

45 Er dürfte hierbei vor allem an die weithin bekannten Panathenäen und Dionysien und die damit verbundenen Schauspiele und Schaustellungen jeder Art gedacht haben. Näheres hierzu siehe im klassischen Werk von LUDWIG DeUBNER: Attische Feste, Berlin 1932. 
auch Rhodos in der griechischen Welt besessen haben, wie kürzlich Klaus Bringmann eingehend dargelegt hat. ${ }^{46}$ Athen und Rhodos als große See- und Handelsmetropolen, doch auch Delphi und Olympia als religiöse Zentren und Austragungsorte panhellenischer Spiele boten ideale Rahmenbedingungen für die Vermittlung höherer intellektueller Bildung (paideia). Was diese für Wandergelehrte jeder Art vor allem interessant machte, war das internationale Forum, das weitgestreute Publikum, die 'Bildungsreisenden' aus allen Teilen der griechischen Welt, die man dort antreffen konnte; denn diese waren aufgeschlossen und zahlungskräftig und konnten darüber hinaus nach der Rückkehr in ihre Heimatstädte maßgeblich dazu beitragen, die Lehrer, die sie gehört hatten, gewissermaßen 'international' bekannt zu machen.

Die 'Biographien' zweier Kolophonier, die sich etwa zwischen 150 und 140 v. Chr. zu Studienzwecken (schole) nach Athen ${ }^{47}$ bzw. Rhodos begaben, zeigen musterhaft, wie eine im lokalen Gymnasion im Rahmen der Ephebie empfangene Paideia in den beiden genannten Bildungsmetropolen vertieft wurde: Im Anschluß an eine Festgesandtschaft verblieb Menippos in Athen und ,nahm (dort) am Unterricht der besten Professoren teil“". ${ }^{48}$ Sicherlich traf er in der Akademie auf Karneades, im Lykeion oder Ptolemaion auf den stoischen Schulvorstand Diogenes von Seleukeia. Ähnliches wird von Polemaios berichtet, der zunächst dafür gerühmt wird, daß er ,sich noch in der sich der Ephebie anschließenden Altersstufe beständig im (heimischen) Gymnasion aufhielt, wobei er seiner Seele mit den schönsten Studien zusätzliche Nahrung verschaffte und seinen Körper durch regelmäßige sportliche Übungen trainierte“. Es wird dann im folgenden berichtet, wie er nach erfolgreicher Erledigung einer diplomatischen Angelegenheit in Rhodos ,,auch den Unterricht der besten Professoren besuchte ${ }^{649}$ - offenbar für längere Zeit, wie im weiteren berichtet wird; denn wie Menippos nimmt er als Mitglied einer Theoria-Abordnung seiner Heimatstadt den Auf-

46 BRINGMANN, Chiron 32, 2002, 73-77. Die Größe und Bedeutsamkeit der öffentlichen Schuleinrichtungen in Rhodos belegt mittelbar die große Getreidestiftung des Eumenes II. Soter, die er 161/160 v. Chr. den Rhodiern zukommen ließ. Der jährliche Mindestertrag dürfte sich nach Abzug der Frachtkosten auf etwa 75.600 Drachmen belaufen haben Polyb. 31,31,1-3 = Schenkungen 212 [L] (mit Kommentar, S. 243): Auch wenn möglicherweise die Hälfte davon nochmals für Feste und Opfer verbraucht wurden, so hätte man mit der verbleibenden Summe immer noch ca. 90 (!) Lehrer mit einem durchschnittlichen Jahresgehalt von 500 Drachmen bezahlen können. Vgl. damit die Stiftungen in Milet $(3.300=8$ Lehrer) und Teos (3.900 Drachmen $=6$ Lehrer), Delphi (1.100 Drachmen $=2$ Lehrer).

47 Weitere Beispiele für Athen bietet das athenische Ehrendekret für einen unbekannten Pergamener (möglicherweise Hegesinous, der später Euandros in der Leitung der Akademie folgte) aus dem Jahr 200/197

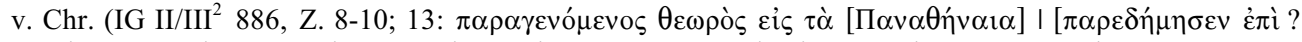

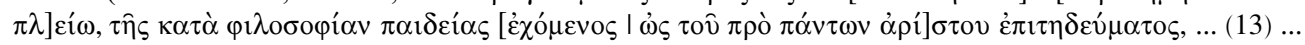

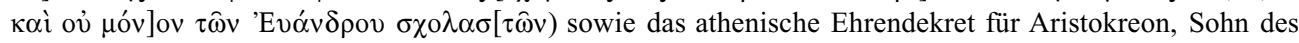
Nausikrates, aus Soloi, den Neffen des stoischen Scholarchen Chrysippos aus dem Jahr 184/183 v. Chr. (IG

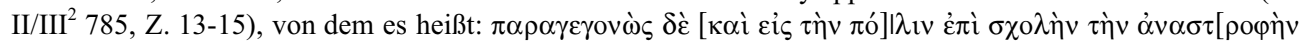
$\varepsilon v ่ \sigma \chi \eta \mu o ́] v \omega \varsigma \pi \varepsilon \pi o ́ \eta \tau \alpha l$. Vgl. damit einige Formulierungen in den Viten verschiedener Philosophen bei Diogenes Laertius.

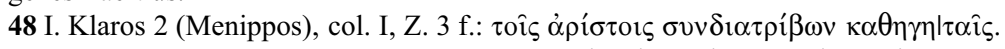

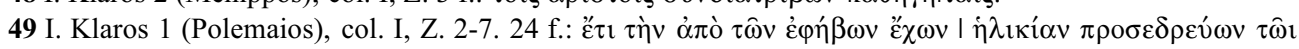

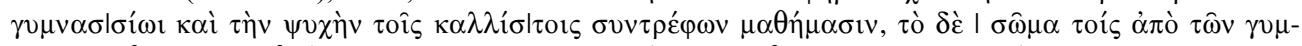

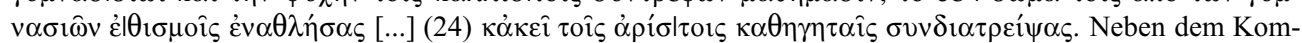
mentar von Louis und Jeanne Robert (I. Klaros, bes. 23-25) siehe zu den beiden Dekreten neuerdings auch: LEHMANN, NAWG 1998, 12 f. 


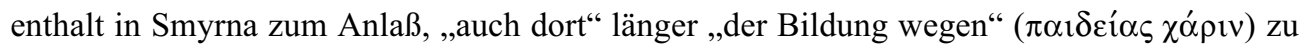
verweilen und „mit den besten Lehrern zusammenzusein“. ${ }^{50}$ Durch die sorgsame Auflistung und Hervorhebung der 'Bildungserlebnisse' bei herausragenden Gelehrten ihrer Zeit werden die beiden Politiker unmißverständlich als $\pi \varepsilon \pi \alpha \imath \delta \varepsilon v \mu \varepsilon ́ v o r$, als Träger philosophisch-rhetorischer paideia charakterisiert und eben darin als Mitglieder der führenden Gesellschaftsschicht erkennbar. ${ }^{51}$ Die Zugehörigkeit zu der sozialen Elite beruhte dabei gleichwohl, wie man betonen muß, nach wie vor auf den politischen Leistungen, jedoch sind diese - zumindest dem Wortlaut dieses späthellenistischen Zeugnisses nach - grundsätzlich nur vorstellbar auf der Basis einer umfassenden Bildung. Diese paideia wurde, wie das Beispiel des Polemaios vermuten läßt, auch nach Abschluß der Ephebie kultiviert und der Kontakt zu bedeutenden zeitgenössischen Gelehrten gesucht. ${ }^{52}$

Die intellektuellen Autoritäten ( $\kappa \theta \eta \gamma \eta \tau \alpha i ́)$, die Menippos in Athen und Polemaios in Smyrna und Rhodos hörten, waren Gelehrte, die sich in den genannten Städten dauerhaft niedergelassen und Schulen gegründet hatten. ${ }^{53}$ Leider sind uns nur für Athen, und hier auch nur für die Philosophenschulen, nähere Einzelheiten zu Gründung, Organisation und Entwicklung des Unterrichts und des sozialen Umfelds der Vermittlung höherer intellektueller Bildung bekannt: Während der Unterricht bei den Rhetoren aufgrund seiner praktischen Verwertbarkeit in Athen spätestens seit dem Beginn des 4. Jh. v. Chr. breite Anerkennung gefunden hatte, fand die Philosophie erst im Laufe des 3. Jh. v. Chr. Aufnahme in den allgemeinen Bildungskanon, und befanden sich ihre Repräsentanten zumeist in einer prekären Lage, was ihre ökonomische Grundlage, den Rechtsstatus und das Sozialprestige betraf. In diesem Zusammenhang ist daran zu erinnern, daß Platon und Epikur es nur aufgrund ihres Bürgerstatus möglich gewesen war, ein privates Grundstück zu erwerben, was konstitutiv für die Institutionalisierung der Schule und deren weiteren Fortbestand war. Der Peripatos, der in seiner Gründungsphase keinen Athener als Schulvorstand besaß, verdankte das

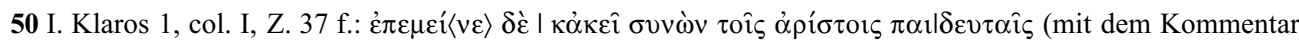
von Louis und Jeanne Robert, I. Klaros, 26 f.). Polemaios wird wahrscheinlich dort das 'Mimnermeion' besucht haben, da dies allem Anschein nach das Gymnasion der véot war, wie eine Inschrift aus dem 1. Jh.

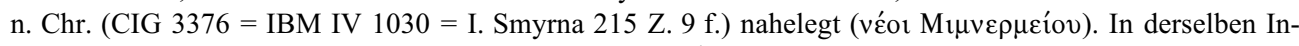

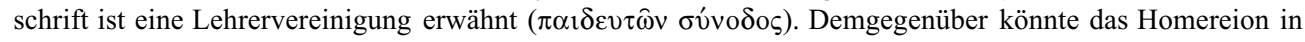
Smyrna der Ausbildung der Kinder und Epheben gedient haben (in diesem Sinne: ZIEBARTH: Schulwesen, 52). DELORME: Gymnasion, $134 \mathrm{f}$. zieht in Zweifel, ob es sich überhaupt um ein Gymnasion handelte.

51 Ein wesentliches Merkmal, das einen Griechen für die Aufnahme in den Kreis der 'Freunde' eines hellenistischen Königs empfahl, waren herausragende intellektuelle und künstlerische Fähigkeiten, siehe hierzu: HABICHT, VSWG 45, 1958, 7 f. Dieser Kreis 'gebildeter' Politiker ( $\pi \varepsilon \pi \alpha \imath \delta \varepsilon v \mu \varepsilon ́ v o r)$ stellte das Publikum für die zahlreichen Dichter, Philosophen und Fachgelehrte dar, die sich an den hellenistischen Höfen aufhielten: WEBER: Dichtung, 122-164.

52 Siehe unten und die diesbezüglichen Bemerkungen zum Bildungshorizont der Gymnasiarchen von Christof Schuler in diesem Band.

53 Auch der Römer L. Saufeius bezeichnet den Epikureer Phaidros auf einer Herme, die er diesem in dank-

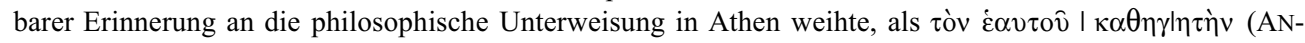
TONY E. RAUBITSCHEK, Hesperia 18, 1949, 101 f., Nr. 1 = Agora Inv. I 5485). Ansonsten wird der terminus in Inschriften im Zusammenhang mit der Ephebenausbildung gebraucht, siehe etwa GVI 2081 (milesische Grabinschrift, 1. Jh. v. Chr.); IG XII 5, 39, Z. 2 f. (Ephebenliste aus Naxos, Ende des 1. Jh. v. Chr.). Vgl. I. Coll. Froehner, S. 56 f. (mit einigen kaiserzeitlichen Belegen), demzufolge $\kappa \alpha \theta \eta \gamma \eta \tau$ í $\varsigma$ vor allem den Grammatiker, Rhetoren oder Philosophen bezeichnet. Zum Gebrauch dieses Begriffs in den Papyri: CRIBIORE: Writing, 16 f.; 167 (mit der Definition: ,private teachers who taught at various levels of education“). 
Grundstück, das Eigentum der Schule war, wie die Testamente der Vorsteher zeigen, der Hilfe des Demetrios von Phaleron, der als ehemaliger Schüler des Aristoteles das Grundstück seinem Nachfolger Theophrast schenkte. ${ }^{54}$ Die günstige Überlieferungslage zu den athenischen Philosophenschulen läßt freilich leicht vergessen, daß diese seßhafte Lebensweise im Schutz dieser speziellen Gelehrteninstitution durchaus nicht den Regelfall der philosophischen wie überhaupt der gelehrten Existenz im Hellenismus darstellte. Alle Gelehrte, die nicht von ihrem Vermögen leben konnten, mußten entweder, sofern die Umstände günstig waren, seßhaft werden und, wie erläutert, Schulen gründen, an einem hellenistischen Herrscherhof als Prinzenerzieher wirken oder als Wanderlehrer ${ }^{55}$ die Gymnasien der griechischen Welt bereisen.

Da es Fremden im allgemeinen in den griechischen Städten untersagt war, Häuser oder Grundbesitz zu erwerben, waren die Gelehrten gezwungen, ihren Unterricht auf öffentlichen Plätzen, in Gymnasien, Palästren oder Stoen unter Aufsicht städtischer Magistrate abzuhalten. Entsprechend mußten sie Rücksicht auf jene und die 'Sitten der Stadt' nehmen und gegebenfalls manche Einschränkung ertragen, zumal gerade die Gymnasien einer strengen Aufsicht unterlagen: Bevor solche Wanderlehrer die öffentliche Institution des Gymnasions zu Unterrichtszwecken nutzen konnten, mußten sie bei dem betreffenden Gymnasiarchen vorstellig werden und sicherlich gemeinsam mit ihm den Schutzgöttern der Gymnasien, Hermes, Herakles und den Musen, opfern. Da man vor allem sexuelle Übergriffe auf freigeborene Knaben seitens der Gymnasionsbesucher fürchtete, wachten die Gymnasiarchen streng über den gesamten Lehrbetrieb. ${ }^{56}$ Begegnungen von Philosophen mit dieser Form von

54 Diog. Laert. 5, 39 = F 10 Fortenbaugh / SChÜtrumpF; vgl. Scholz, Philosoph und Politik, 18-20. $\mathrm{Da}$ Metöken Grund und Boden in Athen erwarben, war äußerst selten: MOSES I. FINLEY: Studies in Land and Credit in Ancient Athens 500-200 B.C. The Horos Inscriptions, New Brunswick 1951, 60.

55 Polyb. 16,14,8-10 nennt die Aussicht auf Geld und Ehre als Motive für das Wirken der Wandergelehrten. $\mathrm{Zu}$ den verschiedenen Arten von Wandergelehrten siehe: MARGHERITA GUARDUCCI: "Poeti vaganti e conferenzieri dell'età ellenistica. Ricerche di epigrafia greca nel campo della letteratura e del costume", MAL 323 (VI 2), 1926, 629-665; Bouvier, ZPE 58, 1985, 119-135 (in Delphi); Christian MAREK: Die Proxenie, Frankfurt am Main 1984, 210-213 (in Delphi); 265-267 (auf Delos); CHANIOTIS: Historie und Historiker, 365-389; WACKER: Gymnasion, 134-137. Den sozialen Status hellenistischer Gelehrter erörtert eingehend: CHRISTES: Bildung und Gesellschaft, 57-71. Speziell zu den philosophischen Wandergelehrten und den Rückwirkungen des Wandergelehrtentums auf das vermittelte philosophische Wissen: PETER SCHOLZ: "Popularisierung philosophischen Wissens im Hellenismus. Das Beispiel der 'Diatriben' des Kynikers Teles”, in: CARSTEN KRETSCHMANN (Hg.): Wissenspopularisierung. Konzepte der Wissensverbreitung im Wandel, (Wissenskultur und gesellschaftlicher Wandel 4), Berlin 2002, 23-45; SCHOLZ: Lyco and Hieronymus.

56 JOHN P. LYNCH: Aristotle's School. Study of a Greek Educational Institution, Berkeley / Los Angeles 1972, 131. So war es in Athen außer den Lehrern niemandem erlaubt, die Schulräume $(\delta 1 \delta \alpha \sigma \kappa \alpha \lambda \varepsilon i \hat{\alpha})$ zu betreten (Aisch. Tim. 12). Hatte ein Gymnasionsbesucher in seinem Betragen oder in seinen Redensarten die Grenzen des Erlaubten überschritten, so lag es ganz im Ermessen des Gymnasiarchen, je nach Schwere des Vergehens den Besucher entweder zu verwarnen oder ihn gewaltsam entfernen zu lassen. Wer sich den Anordnungen des Gymnasiarchen widersetzte oder sogar den Amtsinhaber körperlich zu attackieren wagte,

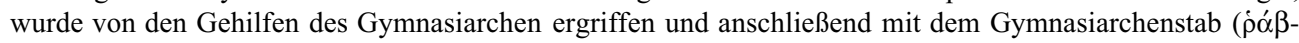
$\delta \circ \varsigma)$ oder einer Peitsche $(\mu \alpha ́ \sigma \tau \iota \xi)$ wieder zur Besinnung gebracht. Siehe die diesbezüglichen Bemerkungen im Gymnasiarchengesetz von Beroia: B 6-10; $39-45$ (mit dem Kommentar von GAUTHIER / HATZOPOULOS, Loi gymnasiarchique, 65-68; 94 f.; vgl. IG XII 7, 515 [Aigiale, 2. Jh. n. Chr.]). Entsprechend wurde in den Dekreten zu Ehren von Gymnasiarchen u.a. deren Strenge ( $\alpha$ $\sigma \tau \eta \rho o ́ \tau \eta \varsigma / \alpha v i \sigma \eta \rho i ́ \alpha)$ hervorgehoben, so etwa: HePding, MDAI(A) 32, 1907, 273, Nr. 10; 279, Nr. 11; JACOBSTHAL, MDAI(A) 33, 1908, 380, Nr. 2. 
'staatlicher' Obrigkeit wurden von der hellenistischen Biographie aufgegriffen und zu anekdotischen Erzählungen umgeformt. Wenn auch die betreffenden Äußerungen der Philosophen kaum als authentisch gelten können, so wird man doch immerhin die Rahmung der Szene, die Konfliktsituation zwischen Philosoph und Gymnasiarch, als historisch gelten lassen können. Drei dieser Anekdoten sind im Werk des Diogenes Laertius bewahrt geblieben: So wurde Karneades in Athen vom Gymnasiarchen ermahnt, beim Vortrag nicht zu 'brüllen', Prodikos soll man aufgefordert haben, das Gymnasion unverzüglich zu verlassen,

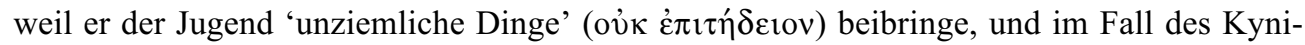
kers Krates soll ein Gymnasiarch in Theben sogleich zur Peitsche gegriffen und ihn wegen seines provozierenden Auftretens aus dem Gymnasion gewiesen haben. ${ }^{57}$ Freilich mußten die Philosophen im allgemeinen eine Ausweisung aus dem Gymnasion und sonstige Sanktionen wohl nur fürchten, wenn sie in der Öffentlichkeit Lehren vertraten, welche die religiösen oder moralischen Vorstellungen der Bürgerschaft grob verletzten, etwa wenn sie sich blasphemisch über die Götter der Stadt äußerten oder den Götterkultus diffamierten. ${ }^{58}$

$\mathrm{Da}$ die philosophische wie überhaupt die intellektuelle Bildung schrittweise in die allgemeine Erziehung integriert wurde und sich bis zu den Rändern der griechischen Welt ausbreiten konnte, lag freilich nicht nur in der sozialen Distinktionsfunktion der intellektuellen Bildung, welche die Oberschicht von den 'ungebildeten' Bürgermassen ( $\alpha \dot{\pi} \alpha i ́ \delta \varepsilon v \tau o r)$ oder Barbaren abgrenzte. ${ }^{59}$ Einen erheblichen Beitrag dazu leisteten sicherlich die Gymnasiarchen in den kleinen und mittelgroßen Städten. ${ }^{60}$ Auch wenn sie nur in Ausnahmefällen bereit

57 Prodikos: [Plat.] Eryx. 399 ab (zwischen 430 und 420 v. Chr.). Krates: Diog. Laert. 6,91 (zwischen 330 und 300 v. Chr.). Karneades: Plut. de garr. 21, p. 513 C (zwischen 195 und 165 v. Chr.), vgl. Diog. Laert. 4,63. Zur Frage der Glaubwürdigkeit dieser Geschichten siehe die treffende Bemerkung von ANTONY A. LONG: "Hellenistic Ethics and Philosophical Power", in: Peter GreEn (Hrsg.): Hellenistic History and Culture, Berkeley / Los Angeles / Oxford 1990, 138-167: „Apocryphal though many biographical anecdotes must be, in the case of the hellenistic philosophers they largely derive from Antigonus of Carystus who was close enough in date to his subject matter to have appeared ridiculous if the general tenor of his biographies was fabrication“ (148). Im Blick auf die rigorose Ablehnung der herkömmlichen Erziehungsmethoden und inhalte wie überhaupt der bürgerlichen Lebensform seitens mancher Philosophen verwundert es nicht, daß wir ausschließlich von Auseinandersetzungen zwischen Philosophen und Gymnasiarchen wissen. Die Anekdoten hatten die Funktion, das öffentliche Auftreten der Philosophen als von der Norm abweichend zu kennzeichnen. An ihnen haftete noch lange Zeit das negative image des Jugendverderbers, siehe hierzu Näheres: SCHOLZ: Philosoph und Politik, 45-51.

58 In diesem Sinne: SCHOLZ: Philosoph und Politik, 69-71; vgl. ROBERT W. WALlaCE: "Private Lives and Public Enemies. Freedom of Thought in Classical Athens", in: Alan Boeghold / Adele C. SCAFuro (Hgg.): Athenian Identity and Civic Ideology, Baltimore / London 1994, 142-146; KEvIN RoBB: Literacy and Paideia in Ancient Greece, New York / Oxford 1994, 205-207; 214-251; Mogens H. HANSEN: The Trial of Socrates from the Athenian Point of View, Kopenhagen 1995, 21; 26.

59 Prägnant formuliert etwa in: Diod. 1,2,5 f. Vgl. KLEIJWEGT: Ancient Youth, 84-86; SCHMIDT: Grabreliefs, $128 \mathrm{f}$.

60 Belege für die Anstellung von Lehrern auf Kosten der Gymnasiarchen: IG XII 9, 234 (RICHARDSON / HEERMANCE, AJA 11, 1896. 173 f.) (Gymnasiarch Elpinikos in Eretria); HePding, MDAI(A) 32, 1907, 279 , Nr. 11 (Pergamon); JACOBSTHAL, MDAI(A) 33, 1908, 376, Nr. 1 (Pergamon). In diesem Zusammenhang ist daran zu erinnern, daß es höchstwahrscheinlich Lykurgos war, der Aristoteles und Theophrast 335 v. Chr. mit seinem Angebot, das jüngst auf seine Kosten erbaute Gymnasion Lykeion zum Ort des philosophischen Unterrichts zu machen, zu einer Rückkehr nach Athen bewegen konnte: ScHOLZ: Philosoph und Politik, $175 \mathrm{f}$. 
waren, das Honorar für Philosophen und andere Gelehrte aus eigenen Mitteln zu zahlen (anderenfalls wäre dieses finanzielle Engagement nicht in den Ehrendekreten eigens erwähnt worden), werden sie, sofern sie sich als 'gebildete Männer' ( $\pi \varepsilon \pi \alpha 1 \delta \varepsilon v \mu \varepsilon ́ v o 1)$ verstanden, die Aufenthalte von Philosophen und anderen Gelehrten zur Unterrichtung der Jugend und Vortragszwecken initiiert, für deren freundliche Aufnahme im Kreis der Gymnasionsnutzer sowie für Bewirtung und Übernachtung gesorgt und diese darüber hinaus mit den führenden Familien der Stadt bekannt gemacht haben. ${ }^{61}$ So kamen etwa während der mehrmaligen Gymnasiarchien des Menas in Sestos eine ganze Reihe von Wandergelehrten in den Genuß von dessen euergetischer Gesinnung, was sorgsam in dessen Ehrendekret vermerkt ist: „Großzügig verhielt er sich auch gegenüber all denjenigen, die Vorträge hielten, da er auch in diesem Bereich durch (den Aufenthalt) kultivierter (Männer) der Vaterstadt zu Ruhm und Glanz verhelfen wollte“. ${ }^{62}$

Diese neuartige, positive Einstellung zu jeglicher Form von intellektueller Bildung dokumentiert besonders eindrucksvoll das samische Ehrendekret für den Peripatetiker Epikrates aus Herakleia. Zugleich gewährt es einen interessanten Einblick in die schwierigen Verhältnisse der philosophischen wie überhaupt der Gelehrtenexistenz. ${ }^{63}$ Die bildungsgeschichtliche Bedeutung dieses Zeugnisses liegt in dem Umstand begründet, daß an der Wende vom 3. zum 2. Jh. v. Chr. zum ersten Mal ein Philosoph ausschließlich aufgrund seiner intellektuellen Tätigkeit geehrt wird. Die Verleihung des Bürgerrechts von Samos wird damit begründet, daß Epikrates ,,sich seit längerer Zeit in unserer Stadt aufgehalten und aufgrund seiner Bildung in vielerlei Hinsicht als Wohltäter der jungen Männer erwiesen hat,

61 Die freundliche Aufnahme von Vorlesungshaltenden durch den Gymnasiarchen wird auch in einem pergamenischen Dekret eigens hervorgehoben: JACOBSTHAL, MDAI(A) 33, 1908, 379-381, Nr. 2 (mit der Korrektur von Martin P. Nilsson in SEG 14, 1957, 765), Agias, Sohn des Agias, wird von Rat und Volk von Per-

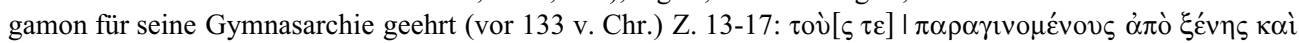

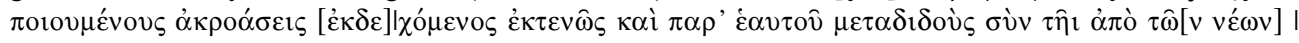

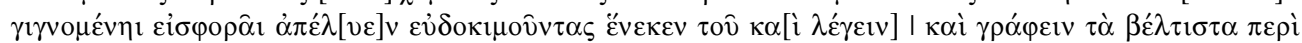
$\tau \hat{\jmath} \varsigma \pi \alpha \tau \rho^{\prime} \delta$ os. Agias zahlt als Gymnasiarch einen Teil der Honorare für mehrere Redner und Historiker, die „aufs Beste“ in Wort und Schrift die pergamenische Geschichte darstellten, der Rest war durch die Abgaben der Jugend gedeckt.

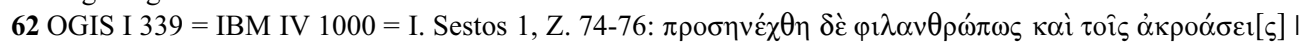

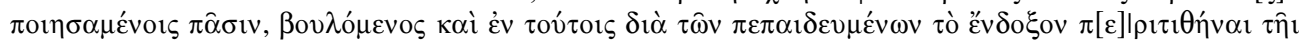
$\pi \alpha \tau$ pídr. Vgl. das Ehrendekret für Stasias aus Perge (EA 11, 1988, 106-109, Nr. 7: 2./1. Jh. v. Chr.), von

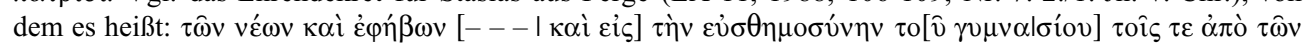

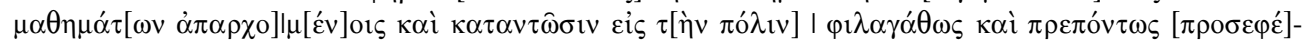

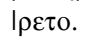

63 IG XII 6, 128. Wenn die auf dem Stil der Schrift basierende Datierung der Inschrift auf die Zeit um 200 v. Chr. richtig ist, muß Epikrates einer der Schüler Lykons (226/225 oder 225/224 v. Chr.) gewesen sein. Sein Geburtsdatum wäre demnach - als ein möglicher Altersgenosse des Ariston von Chios, der Lykon im Schulvorstand nachfolgte - ungefähr in die Zeit um 250 v. Chr. anzusetzen. Zur Chronologie dieser Scholarchen: TIZIANO DORANDI, Ricerche sulla cronologia dei filosofi ellenistici, Stuttgart 1991, $68 \mathrm{f}$. Zu Samos als einem lokalen kulturellen Zentrum im 3. Jh. v. Chr.: GRAHAM A. SHIPLEY: A History of Samos, 800-188 B.C., Oxford 1987, 226 f. Walter Ameling (in diesem Band, S. 156 Anm. 177) hält Epikrates m.E. zu Un-

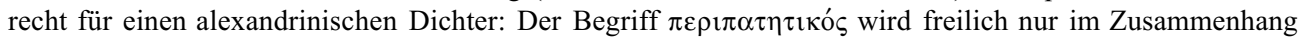
mit der Schule des Aristoteles gebraucht. Sämtliche diesbezüglichen Belege stammen aus philosophischen

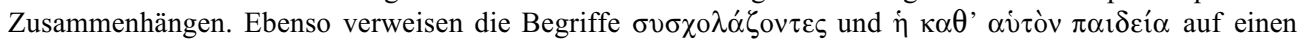
philosophischen Kontext. 
indem er sich sowohl im persönlichen Umgang den hier (immer wieder neu) Hinzukommenden unter seinen Schulgenossen als auch öffentlich dem Volk gefällig erweisen wollte. Dabei gewährte er jedem Bürger, der daran teilhaben wollte, in reichem Maße Zugang zu der Bildung in seinem Sinne und unterrichtete Männer aus dem einfachen Volk, die das von ihm festgesetzte Unterrichtsgeld nicht zahlen konnten, sogar kostenlos“.

Epikrates tritt als Lehrer und Führer einer Gruppe auf, die sich in Samos neu um ihn scharte und dort eine Lehr- und Lebensgemeinschaft $(\sigma v \sigma \chi 0 \lambda \alpha \dot{\alpha} \text { ov } \tau \varepsilon \varsigma)^{64}$ begründete. Im Gegensatz zu vielen anderen Gelehrten war es ihm also bemerkenswerterweise gelungen, seinen prekären Status als Wandergelehrter in eine zumindest zeitweise seßhafte Existenz (außerhalb seiner Heimatstadt) zu überführen. Dabei fiel ihm wie überhaupt allen intellektuellen Lehrmeistern, gleichgültig, ob sie nun Wandergelehrte waren oder eine seßhafte Variante ihres Berufsstandes repräsentierten, notwendigerweise auch die patronale Fürsorgepflicht für ihre Begleiter zu, sich den Schülern gegenüber „gefällig zu erweisen“ (wie es in Zeile 17 heißt: $\chi \alpha \rho i ́ \zeta \varepsilon \sigma \theta \alpha$ ), also für deren leibliches und seelisches Wohlergehen zu sorgen - etwa in der Art, wie es in einer Anekdote von Aristippos berichtet wird: Dieser wird für seine philosophischen Erörterungen im Gymnasion von Rhodos mit so großen Geldgeschenken überhäuft, daß er ,nicht nur sich selbst ausstatten, sondern auch seinen Begleitern Kleider und den notwendigen Lebensunterhalt finanzieren konnte ". ${ }^{65}$ Üblicherweise wurden vor allem Philosophen auf ihren Reisen durch die griechische Welt von Schülern begleitet, was nicht verwundert, da die Schüler bzw. Anhänger, die ihnen überallhin treu folgten, gerade darin ihr Bekenntnis zur philosophischen Lebensform unter Beweis stellten. Besonders anschaulich ist dies in einer Anekdote um Bion von Borysthenes belegt: Bion, der über keinen festen Anhängerkreis verfügte, ${ }^{66}$ soll einige Seeleute überredet haben, 'Schulkleidung'

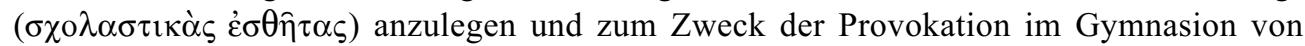
Rhodos als seine Schüler aufzutreten. Mag es sich so zugetragen haben oder nicht - die Geschichte weist jedenfalls darauf hin, daß die Epheben oder andere Teilnehmer der $\sigma \chi 0 \lambda \alpha i ́$ auch in Rhodos durch ihre Kleidung als solche kenntlich waren, und es zudem nicht ungewöhnlich war, wenn ein Wanderlehrer mit einer Schar von Anhängern in das örtliche Gymnasion einzog und sich so effektvoll beim lokalen Publikum einführte.

64 Zum Begriff, der offenkundig den inneren Schülerkreis bezeichnet: Diog. Laert. 5,52 (aus Theophrasts

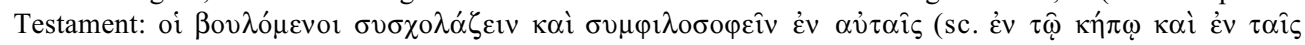
оікі́(1).

65 Vitr. 6 praef. 1 = Aristippos 9 B MANNEBACH = I A 43 GIANNANTONI. Weitere Belege für die Dankbarkeit von Schülern über die im Unterricht vermittelten Kenntnisse: I. Sestos 5. (Ehrung des Geometer Asklepiades durch die neoi, Epheben, paides und paideutai); GVI 1916 = IG XII 1, 141 (Grabepigramm für einen

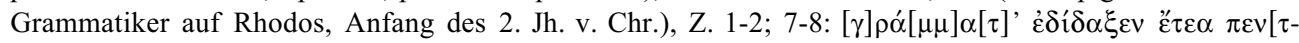

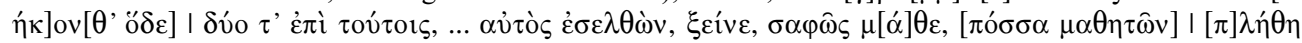

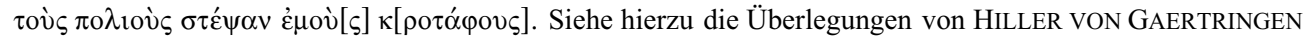
/ ROBERT, Hermes 37, 1902, 140-142).

66 Diog. Laert. 4,53 = Bion T 3 KindSTRAND (mit dem Kommentar von JAN F. KinDSTRAND: Bion of Borysthenes. A Collection of the Fragments, Stockholm 1976, 138 f.); vgl. zu dieser Anekdote auch LUDWIG RADERMACHER: Weinen und Lachen. Studien über antikes Lebensgefühl, Wien 1947, $120 \mathrm{f}$. In diesem Zusammenhang ist darauf hinzuweisen, daß Bion durchaus von Hieronymos oder Arideikes nach Rhodos eingeladen worden sein könnte (vgl. Diog. Laert. 4,49 = Bion F 4 KINDSTRAND). Die drei müssen nämlich ungefähr Zeitgenossen sein und zur selben Zeit und wohl auch in den gleichen Schulen ihre Studienzeit in Athen verbracht haben, denn Bion nahm sowohl am Unterricht im Peripatos als auch in der Akademie teil. 
Epikrates und seine $\sigma v \sigma \chi 0 \lambda \alpha ́ \zeta o v \tau \varepsilon \varsigma$ müssen sich zumindest mehrere Monate, wenn nicht sogar Jahre auf Samos aufgehalten haben. Neben den Erörterungen im kleinen Kreis der vertrauten Schüler wirkte er dort auch in der Öffentlichkeit, nämlich als Lehrer der Paideia im philosophischen Sinne, wie es in Zeile 18 heißt: $\dot{\eta} \kappa \alpha \theta$ ' $\alpha \dot{v} \tau$ òv $\pi \alpha \imath \delta \varepsilon \varepsilon^{\prime} \alpha .{ }^{67}$ Die finanziellen Mittel, die für eine solche philosophische Paideia erforderlich waren, die Schiffsreise, die Lehrerhonorare, die Bewirtungs-, Übernachtungs und Austattungskosten für die Söhne etc., konnten freilich in der Regel nur von einem kleinen Teil der Bevölkerung in den griechischen Städten aufgebracht werden. Selbst die intellektuelle Ausbildung im heimischen Gymnasion war, wie die Epikrates-Inschrift zeigt, vom Großteil der Bürger nicht zu bezahlen. Entsprechend wird es in dem Ehrendekret als außergewöhnliche euergetische Tat gewürdigt und lobend hervorgehoben, daß der peripatetische Philosoph während seines gesamten Aufenthalts auf Samos keinen Lohn für die Unterrichtung des Teils der städtischen Jugend verlangte, der zwar ebenso wißbegierig wie dessen Altersgenossen, jedoch nicht in der Lage war, eine höhere Bildung zu finanzieren. ${ }^{68}$

Doch in welcher Form wurde intellektuelle Bildung in den griechischen Gymnasien vermittelt? In der literarischen und epigraphischen Überlieferung werden immer wieder

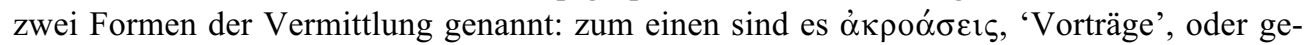
nauer gesagt, vor einem öffentlichen Publikum von Gymnasionsbesuchern inszenierte einmalige Darbietungen der eigenen Kunst in Form von Lehrvorträgen, Stegreifreden, Gedichtrezitationen, musikalischen und gesanglichen Darbietungen. Zum anderen ist die Rede von $\sigma \chi 0 \lambda \alpha i$, worunter regelmäßige Unterrichtskurse in kleinen Gruppen zu verstehen sind, die von den Schülern bezahlt werden mußten und sich über einen gewissen Zeitraum hinzogen. ${ }^{6}$

Erstere richteten sich an ein weites Publikum, das die städtischen Epheben ebenso umfaßte wie die neoi und übrigen gebildeten Bürger, letztlich an eine gesamtgriechische Öffentlichkeit; denn die jeweilige Darbietung konnte und sollte nicht nur an einem Ort, sondern in allen Städten bzw. Gymnasien der griechischen Welt dargeboten werden. ${ }^{70}$ Gerade

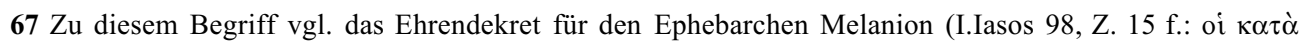
$\varphi \imath \lambda$ обофíav $\lambda$ ó ${ }^{\circ}$ ) s sowie das Ehrendekret für einen unbekannten Pergamener und Schüler des Euandros (IG

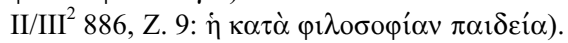

68 Ein weiteres Beispiel für eine unentgeltliche Probe seines intellektuellen Könnens gab zu Anfang des 1. Jh. v. Chr. der Grammatiker Menandros in Delphi: FD III 3, 338 = BOUVIER, ZPE 58, 1985, 133 Nr. 71 (Text siehe unten, Anm. 79). Ansonsten war finanzielle Unabhängigkeit eine unverzichtbare Voraussetzung für ein mehrjähriges Studium, zumal wenn dieses in der Fremde absolviert wurde, da mit dem philosophischen Unterricht ein äußerst aufwendiger Lebensstil verbunden war, siehe hierzu insb. Teles 40-41; 46 HENSE; vgl. Stob. anthol. 2,31,124 = Theophrastus F 465 FORTENBAUGH; an inschriftlichen Zeugnissen ist beispielhaft auf die Dekrete zu Ehren des Menippos und Polemaios aus Kolophon zu verweisen (Anm. 45).

69 Siehe die entsprechende Formulierung etwa im Ehrendekret für einen Philosophen aus dem böotischen

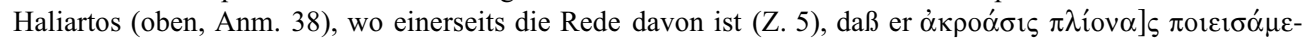

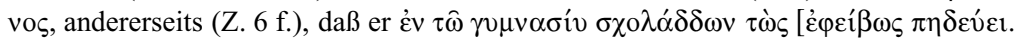

70 Das kommt etwa zum Ausdruck, wenn ein anonymer Autor über Musik (P. Hib. I 13, um 430-380 v. Chr., col. I 1-9) mit folgenden Worten seinen Vortrag einleitet: „Desöfteren, Männer aus Griechenland, erregte es meine Verwunderung, daß Euch entgeht, daß manche Leute Vorträge halten, die mit der eigenen Profession nichts zu tun haben. (Diese Leute) behaupten nämlich, sie seien in der Musik beschlagen, wählen einige Lieder aus und geben über diese Urteile ab, wobei sie einen Teil von ihnen nach Gutdünken kritisieren, einen anderen ohne Grund loben. (2) Sie sagen ferner, daß man sie weder als Saitenspieler noch als 
weil die Wandergelehrten sich gegenüber Konkurrenten abgrenzen und hervorheben mußten, war es bei den $\alpha \kappa \rho о \alpha ́ \sigma \varepsilon \imath \varsigma$ üblich, an den Vorgängern oder zeitgenössischen Konkurrenten harsch und unverhohlen Kritik zu üben. Dazu gehörte es, aktuelle Debatten aufzugreifen, einen imaginären Agon mit den Vertretern konkurrierender Ansichten zu inszenieren und den Zuhörern anhand einzelner Beispiele die Überlegenheit der eigenen Einsicht eindrücklich zu demonstrieren. Nicht nur vor Gericht und in der Volksversammlung, sondern auch im Gymnasion war das Volk die entscheidende urteilende Instanz, vor der eine Darbietung in erster Linie zu bestehen hatte. Das bedeutete wiederum, daß in erster Linie nicht die Logik des besseren Arguments, sondern vielmehr die Unterhaltung des Publikums im Vordergrund stand. ${ }^{71}$

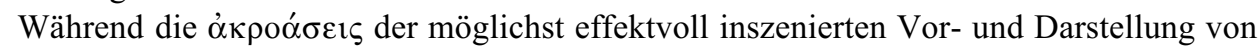
Lehrer und Lehre sowie der Anwerbung zahlungskräftiger Schüler dienten, waren die $\sigma \chi 0 \lambda \alpha i$ gewissermaßen das 'Produkt', das die Wandergelehrten verkauften. Mit ihnen bestritten die Gelehrten und Lehrer ihren Lebensunterhalt - also mit Kursen, die in einem kleinen Kreis, Schüler und Lehrer auf einer Exedra sitzend, abgehalten, in denen Argumentationen geübt oder Musterreden vorgetragen und diskutiert wurden. ${ }^{72}$ Im Grabrelief des Peripatetikers Hieronymos von Tlos liegt uns eine bildliche Darstellung einer philosophischen Gesprächsszene in gymnasialer Umgebung ( $\sigma \chi 0 \lambda \eta ́)$ vor, die die einzige aus hellenistischer Zeit ist. ${ }^{73}$

Sänger ansehen dürfe, denn die (praktische Ausübung) überließen sie anderen, wie sie behaupten, ihr Gebiet sei vielmehr die theoretische Ebene“. Der namenslose Autor übt scharfe Kritik an sog. reinen Musiktheoretikern, die Theorien über die Auswirkungen bestimmter Tonarten auf Moral und Charakter der Zuhörer anstellten, ohne allerdings selbst über professionelle Fähigkeiten als Sänger und Saitenspieler zu verfügen. Zur Interpretation: WILHELM CRÖNERT: "Die Hibehrede über die Musik", Hermes 44, 1909, 503-521; WILHELM NeSTLE: Vom Mythos zum Logos. Die Selbstentfaltung des griechischen Denkens von Homer bis auf die Sophistik und Sokrates, Stuttgart ${ }^{2} 1941,435-437$.

71 Eben wegen dieser mehr auf performative und rhetorische Effekte orientierten als an Wahrheitsforschung interessierten Vortragspraxis kritisierte etwa Thukydides die Logographen $(1,21 \mathrm{f}$.) und hielt ihnen selbst-

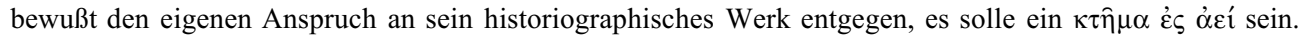
Man unterschätzt in der Regel in der modernen Forschung die Rolle dieser Lesungen in den Gymnasien wie auch das Ausmaß der Prägung, die viele Gattungen der griechischen Literatur dadurch erfuhren, und überschätzt die Rolle der Lektüre von Texten. Ideen, neue Denkweisen und Wissen wurden eher durch eindrucksvolle mündliche Schaustellungen vermittelt als auf schriftlichem Wege. Siehe hierzu umfassend: RoSALIND THOMAS: Literacy and Orality in Ancient Greece, Cambridge 1992.

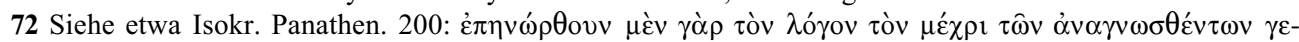

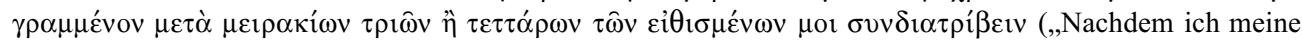
Rede niedergeschrieben hatte, bis zu dem Punkt, zu dem ich gekommen war, korrigierte ich ihn mit drei oder vier jungen Männern, die es gewohnt waren ihre Zeit mit mir zu verbringen“). In Rhodos wird ein Unbekannter im 3. Jh. v. Chr. von verschiedenen örtlichen Magistraten und Vereinen geehrt (PUGLIESE CARRA-

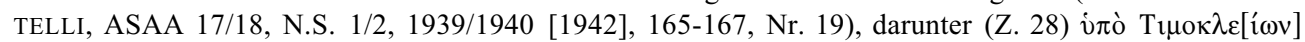

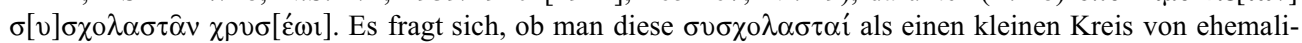
gen 'Schulkameraden' auffassen soll.

73 SMPK Berlin, Pergamonmuseum, Inventar-Nr. Sk 1888; PfUHL / MöBIUS: Grabreliefs II 2085, 501 mit Tf. 300 (mit der älteren Literatur). Erstmals publiziert in: HILLER VON GAERTRINGEN / ROBERT, Hermes 37, 1902, 121-146, Tf. 1. Zur Interpretation der philosophischen Szene siehe demnächst ausführlich (mit neuerer Literatur): SCHOLZ: Lyco and Hieronymus. Dargestellt ist eine Gruppe von fünf Männern; drei von ihnen sitzen dabei auf einer freistehenden Exedra, die schon durch ihre Verzierung mit Löwenfüßen, erst recht aber dadurch als solche identifiziert werden kann, daß sie leicht schräg aus dem Relief herausgestellt ist, was den 
Daß die Aufenthalte und Lesungen der Wandergelehrten in den Gymnasien außerordentliche und vielbeachtete Ereignisse waren, zeigt die große Zahl inschriftlicher Belege für Ehrungen von Wandergelehrten verschiedenster Art in Städten und Heiligtümern. Die meisten Zeugnisse liegen für Historiker vor, die Partien aus ihren Geschichtswerken vorstellten und dabei die ruhmreiche Vergangenheit der Städte und Heiligtümer beschworen oder auch Enkomien auf die Römer „,als Euergeten der Griechen“ hielten. ${ }^{74}$ Sie müssen freilich nicht tatsächlich die quantitativ stärkste Gruppe gewesen sein, da sie durch den unmittelbaren praktischen Nutzen ihrer Tätigkeit für die städtische Gemeinschaft sicherlich die größten Aussichten besaßen, öffentliche Anerkennung in Form eines Ehrendekrets zu erhalten. Es folgen die Rhetoren, die sich über die Kunst der Rede ausließen oder praktische rhetorische Übungen für all diejenigen durchführten, die „Nutzen von derartigen Dingen empfangen

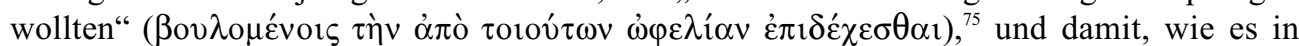
einem anderen Dekret um 100 v. Chr. heißt, ,,den besten und ersten Bürgern zu einem Fortschritt in der Bildung und in den Logoi und der Stadt zu guten Männern verhalfen“. ${ }^{76}$ Als

Eindruck vom Halbrund der Sitzbank optisch verstärkt. Die zwei stehenden, von der Statur etwas kleineren und damit als jünger charakterisierten Figuren sind wohl als Söhne des Hieronymos anzusehen, die ihre Hände auf den Rücken des Vaters gelegt haben und damit ihre Verbundenheit mit diesem signalisieren. Der 'Vater' Hieronymos sitzt leicht vorgebeugt, in einen Mantel gehüllt, und wie sein älterer Sohn mit einem Bürgerstock in der Hand, und lauscht den Worten seines Gegenübers, der seine Unterarme auf die Oberschenkel gelegt hat und mit den Händen die beiden Enden einer aufgerollten Buchrolle hält. Neben ihm sitzt eine weitere, allerdings kaum noch sichtbare männliche Figur auf der Steinbank.

74 Aristotheos, Sohn des Nikotheos, aus Troizen erhält in Delphi um die Mitte des 2. Jh. v. Chr. die Proxe-

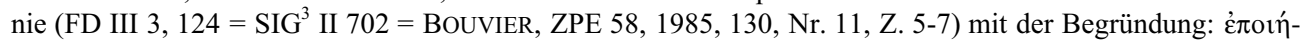

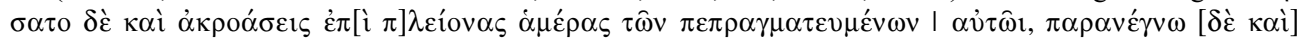

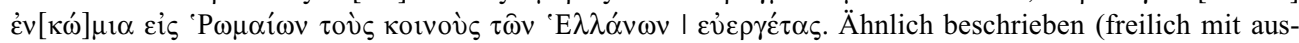
drücklicher Erwähnung des Gymnasion) findet sich die Vortragstätigkeit des Bombos, Sohn des Alpheios, aus Alexandreia Troas (BÉQUIGNON, BCH 1935, 55 f. = CHANIOTIS: Historie und Historiker, 310 f., E 18)

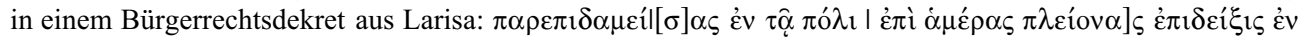

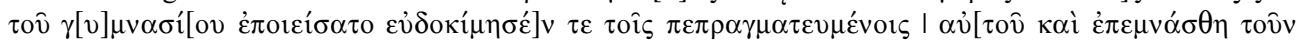

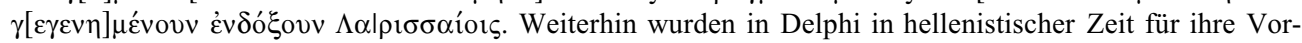
tragstätigkeit die Historiker geehrt: FD III 1, 429 = BOUVIER, ZPE 58, 1985, 134, Nr. 75 (Neanthes, Sohn des Nikotelos, aus Kyzikos im 3. Jh. v. Chr.); $\mathrm{SIG}^{3}$ II 585, 114 = BouVIER, ZPE 58, 1985, 134, Nr. 79 (Polemon, Sohn des Milesios, aus Ilion, im 2. Jh. v. Chr.); FD III 4, 145 = BOUVIER, ZPE 58, 1985, 132, Nr. 49 (C. Iulios Theopompos, Sohn des Artemidoros, aus Knidos im 1. Jh. v. Chr.).

75 Elpinikos, Sohn des Nikomachos, wird in Eretria für seine Gymnasiarchie um 100 v. Chr. geehrt (IG XII

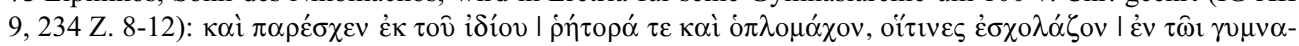

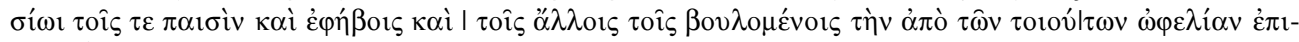
$\delta \varepsilon \chi \chi \varepsilon \sigma \theta \alpha$. Themistokles, Sohn des Aischylos, aus Ilion wird von der Polis und den Archonten von Xanthos

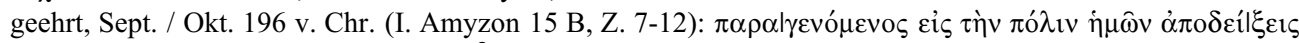

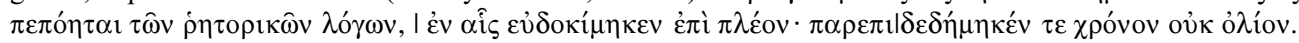
Der Römer D. Iunius erhält Proxenie und andere Privilegien in Delphi im 1. Jh. v. Chr. (LOUIS ROBERT: "Fêtes, musiciens et athlètes 2. Décret de Delphes pour un rhéteur romain", in: ders.: Études epigraphiques

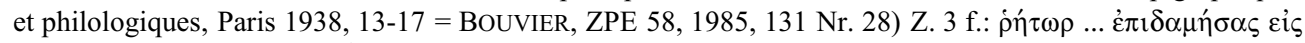

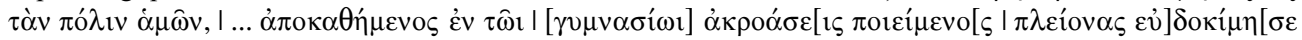
(,weil er auf seiner Reise in unsere Stadt kam, sich im Gymnasion niederließ und mehrere Vorträge veranstaltete, verschaffte er sich hohes Ansehen“). Eine weitere Ehrung eines Rhetors in Delphi: siehe die folgende Anm.

$76 \mathrm{Im}$ delphischen Proxeniedekret für den Rhetoriklehrer Artemidoros, Sohn des Eubulos, aus Mazaka und Athen (FD III 4, 59 = BouvIER, ZPE 58, 1985, 130, Nr. 17, Anfang des 1. Jh. v. Chr.), heißt es in Z. 7-9: 
dritte Gruppe von Wandergelehrten sind die Philosophen zu nennen, die bereits im Zusammenhang mit dem samischen Ehrendekret für den Peripatetiker Epikrates vorgestellt wurden. ${ }^{77}$ Als vierte Gruppe waren die Homerphilologen und Grammatiker durch ihren Aufent-

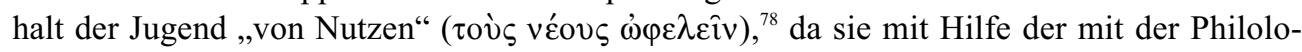
gie verbundenen Wissensgebiete, wie in einer der Inschrift zu lesen ist, „die Seelen (der

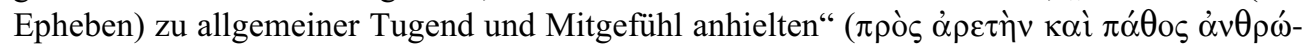

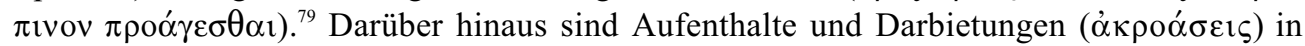
verschiedenen griechischen Gymnasien für Ependichter, ${ }^{80}$ sowie für einzelne Astrologen, ${ }^{81}$ Geometer, ${ }^{82}$ und Ärzte ${ }^{83}$ bezeugt.

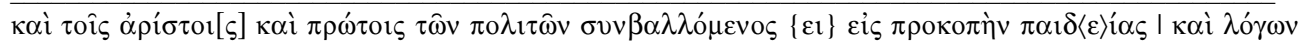

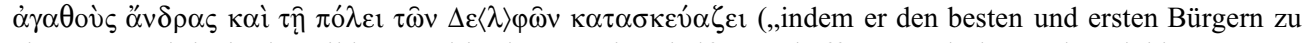
einem Fortschritt in der Bildung und in den Logoi verhalf, verschaffte er auch der Stadt Delphi gute Männer").

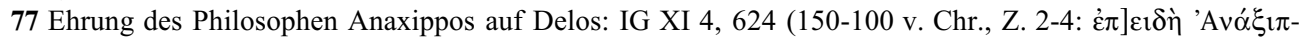
$\pi \circ \varsigma---] \operatorname{ov} \tau \circ \varsigma \alpha[---] \eta \varsigma \varphi \iota \lambda$ oбo $\varphi \mid \hat{\omega}[v---)$. Bei der Ehrung des Laitos im 3. Jh. v. Chr. in Delphi wird der Grund für dieselbe, wie es bei den Kurzeintragungen üblich war, nicht angegeben: FD III 1, 106 = BOUVIER, ZPE 58, 1985, 133. Nr. 66.

78 Der Gymnasiarch Mantidoros, Sohn des Kallikrates, in Eretria stellt Homerphilologen für die älteren

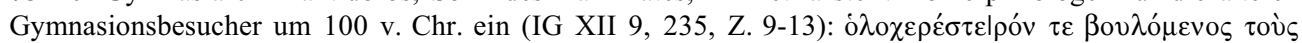

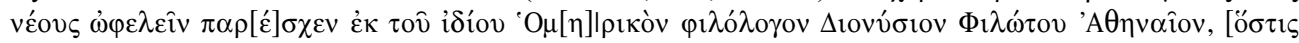

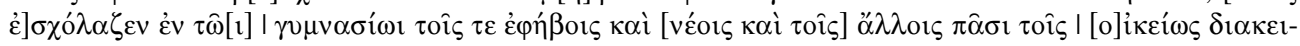

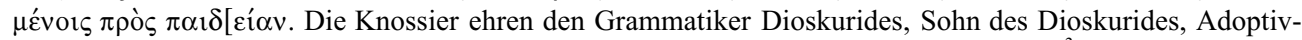
sohn des Asklepiodoros, aus Tarsos gegen Ende des 2. Jh. v. Chr. (I. Delos $1512=$ SIG $^{3}$ II $721=$ I. Kreta I viii 12), weil er ein Enkomion auf die Kreter verfaßte, das sein Schüler, der Ependichter Myrinos aus Ami-

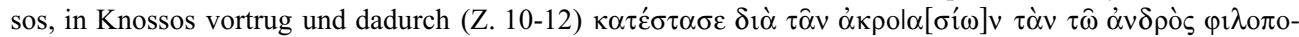

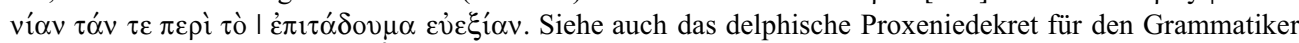
Menandros aus Thyrreion: SIG $^{3}$ II 739 (Text siehe Anm. 78). Eine Sammlung der epigraphischen Belege zu den Grammatikern bietet: SANDRINE AGUSTA-BOULAROT: "Les références aux grammatici et $\gamma \rho \alpha \mu \mu \alpha \tau 1 \kappa o i ́$ de l'Empire romain (I ${ }^{\text {er }}$ s. ap. J.-C. - IV s. ap. J.-C)", MEFRA 106, 1994, 653-746.

79 I. Priene 112 (Begründung der Anstellung eines Grammatikers durch den Gymnasiarchen Zosimos, nach

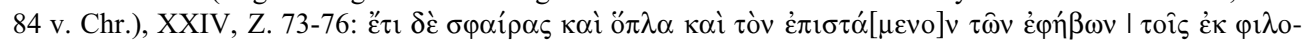

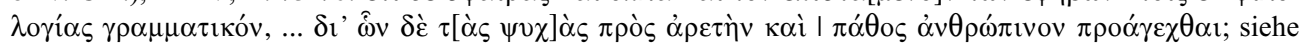

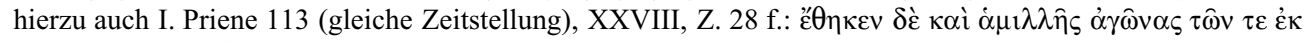
$\varphi ı \lambda \circ \lambda[o] \gamma^{\prime} \mid \alpha \varsigma \mu \alpha \theta \eta \mu \alpha \dot{\tau} \omega v$. In Delphi hält der Grammatiker Menandros, Sohn des Daidalos, aus dem akarnanischen Thyrreion um 84 v. Chr. kostenlos Vorträge (FD III 3, $338=$ SIG $^{3}$ II $739=$ BOUVIER, ZPE 58, 1985,

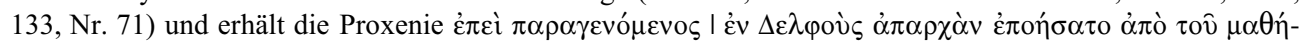

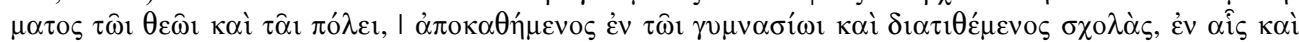

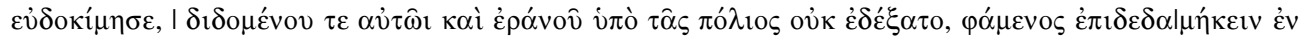

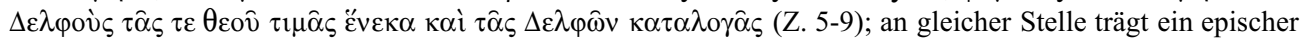
Dichter seit seiner Kindheit Gedichte vor (FD III 1, 273 = siehe die folgende Anm.). In Rhodos unterhält der Grammatiker Aristodemos, Sohn des Grammatikers Menekrates (Schüler Aristarchs) zwei Schulen sowie zwei weitere im karischen Nysa gleichzeitig (Strabo 14,1,48 [p. 650]), dabei Rhetorik morgens, Grammatik abends (vor allem Lektüre und Kommentierung klassischer Texte, ins besondere Homer).

80 FD III 1, 273 (Proxeniedekret für einen unbekannten Ependichter aus Skepsis in Delphi, um 132 v. Chr.),

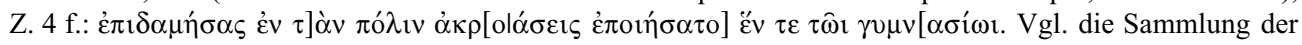
epigraphischen Belege zu den epischen Dichtern und Lyrikern bei CHANIOTIS: Historie und Historiker, 332348, E 51-72.

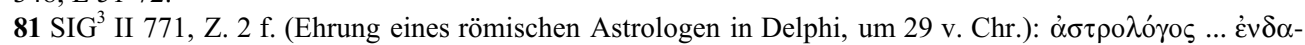

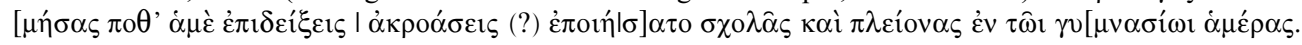
Vgl. das Ehrendekret für den chaldäischen Astronomen Antipatros aus Hieropolis / Seleukis, um 150 v. Chr. 


\section{Die Entstehung öffentlicher Bibliotheken ${ }^{84}$}

Das systematische Büchersammeln nahm seinen Anfang, soweit wir wissen, bei den Philosophen. Besonders Aristoteles spielte hier eine bahnbrechende Rolle. Zumindest in dieser Hinsicht wurde der Peripatos zum Vorbild, dem die anderen Philosophenschulen mit eigenen Büchersammlungen nachzueifern suchten. Den speziellen Bedürfnissen der Philosophen, von denen die Einrichtung von Bibliotheken ausgegangen war, entsprach ein allgemeineres der gebildeten Bürgerschaft, die in der Sammlung von Buchrollen ihre vielfältigen Interessen vertreten haben wollte. Diese reichten von früher Dichtung, Tragödie, Komödie über Historiographie und Rhetorik bis hin zu Medizin, Musik, Mathematik und Astronomie. ${ }^{85}$ Reiche 'gebildete' Bürger ( $\pi \varepsilon \pi \alpha \imath \delta \varepsilon v \mu \varepsilon$ 'vor) fanden sich aufgrund ihrer Vorbildung dazu bereit, als Gymnasiarchen den Aufenthalt von Wandergelehrten im örtlichen Gymnasion zu bezahlen oder für den Aufbau einer Bibliothek Buchrollen zu spenden ${ }^{86}$ Darin brachten sie einerseits ihr Bildungsinteresse zum Ausdruck, zum anderen ließen sie ihre Mitbürger daran teilhaben und trugen so zum eigenen Ruhm und zur Aufwertung des städtischen Prestiges bei, da sich darin gewissermaßen die paideia der Stadt dokumentierte ${ }^{87}$ Sie entsprachen damit zugleich einem im Laufe des 3. Jh. v. Chr. gewachsenen Bildungsbedürfnis.

Zur Gründung einer Bibliothek, die in den Gymnasien kleinerer Städte nicht mehr als aus einer wenige Körbe umfassenden Buchrollensammlung bestanden haben dürfte, waren

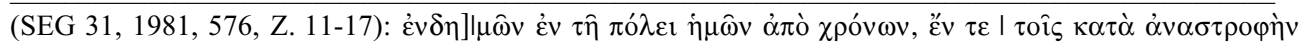

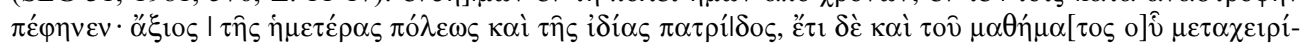

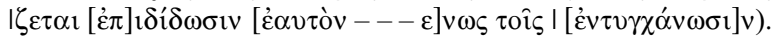

82 Der Geometer Asklepiades, Sohn des Nikomachos, wird in Sestos von den neoi, Epheben, paides und paideutai mit einem Kranz geehrt: I. Sestos 5.

83 Der Arzt Diokles, Sohn des Artemidoros, aus Kyzikos wird von Rat und Volk von Istros im 2. Jh. v. Chr.

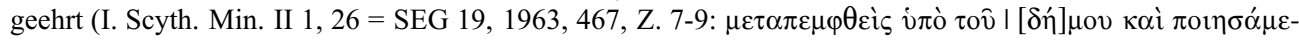

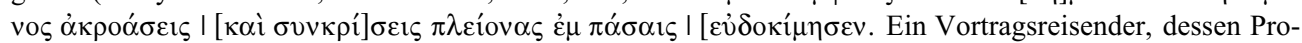
fession unbekannt ist, war auch Amphikles, Sohn des Philoxenos, aus Delos (IG VII 373), der in Oropos

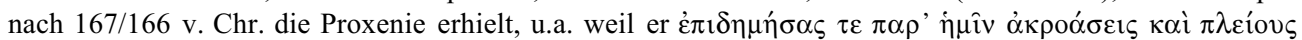
$\pi \varepsilon \pi$ ón $\alpha_{1}$ (Z. 4).

84 In meinen Ausführungen folge ich wesentlich den Überlegungen von DANIEL KAH: "Die Entstehung der öffentlichen Bibliotheken im Hellenismus" (unveröffentlichtes Manuskript), der zur Zeit u.a. ein Corpus der hellenistischen Bibliotheksinschriften (mit den sonstigen literarischen Testimonia und Kommentar) vorbereitet.

$85 \mathrm{Zu}$ den intellektuellen Fertigkeiten und Kenntnissen siehe das eindrückliche Beispiel des teischen Ge-

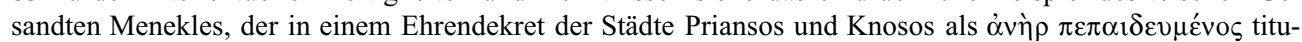
liert wird, da er bei seinen öffentlichen Auftritten Lieder kretischer Dichter „schön und angemessen für einen gebildeten Mann“ vorzutragen verstanden habe: GDI III 2, 5187 = I. Kreta I viii (Knosos) 11, Z. 7-11. Siehe hierzu Näheres bei: ANGElos ChANIOTIS: "Als die Diplomaten noch tanzten und sangen. Zu zwei Dekreten kretischer Städte in Mylasa”, ZPE 71, 1988, 154-156. Vgl. allgemein zum Bildungsideal des $\pi \varepsilon-$

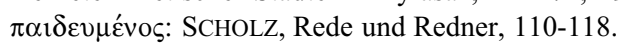

86 Belege für Spenden von Buchrollen: siehe Anm. 90 und 91.

87 Siehe etwa die Bereitschaft des pergamenischen Gymnasiarchen Agias zur finanziellen und materiellen Förderung der intellektuellen Bildung: Die von ihm finanzierten Gehaltsverbesserungen der Lehrer hätten

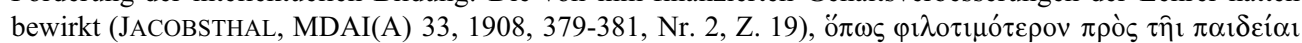

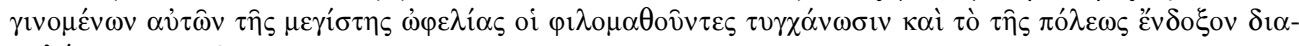
$\varphi v \lambda \alpha ́ \sigma \sigma \eta \tau \alpha$. Vgl. I. Sestos 1. 
in der Regel keine kostspieligen Baumaßnahmen erforderlich, da wohl hierfür oft nicht mehr als ein kleiner Raum innerhalb eines bestehenden Gymnasiumskomplexes benötigt wurde. Wie zuletzt Christian Wacker überzeugend dargelegt hat, wurden in Olympia höchstwahrscheinlich eine oder mehrere der geschlossenen Magazinräume in den Ecken der Nordseite der Palästra als Bibliotheksräume benutzt. ${ }^{88}$ Das aber heißt: Zumindest in hellenistischer Zeit wurden die neuen Einrichtungen in die traditionelle Architektur des Gymnasions integriert und keine architektonische Bauform eigens für die Bibliotheken neu entwickelt.

$\mathrm{Daß}$ bereits im 4. und 3. Jh. v. Chr. die Mehrheit der städtischen Gymnasien über Bibliotheken verfügte, ist eine 'fable convenue' und oft stillschweigend vorausgesetzte Meinung vieler Standardwerke zur antiken Erziehungs- und Bildungsgeschichte. Eindeutige literarische, inschriftliche oder archäologische Belege gibt es für diese Behauptung nicht. ${ }^{89}$ Die ersten als öffentlich, d.h. für jedermann frei zugänglich bezeugten Bibliotheken, die verhältnismäßig sicher datiert werden können, sind diejenigen Pergamons. Bei Strabon (13,4,2 p. $624 \mathrm{c})$ ist von mehreren $\beta \imath \beta \lambda \iota \theta \hat{\eta} \kappa \alpha \iota$ die Rede, mit denen wohl Attalos II., der jüngere Bruder Eumenes' II., die Stadt neben zahlreichen Weihgeschenken ausschmückte. ${ }^{90}$ Das entspricht auch der inschriftlichen Überlieferung, die ebenfalls von mehreren Bibliotheken spricht $\left(\beta \imath \beta \lambda_{\imath} \theta \eta \kappa \omega \hat{v}\right){ }^{91}$ Es gab also in Pergamon spätestens gegen Ende des 2 . Jh. v. Chr. mehrere von den Königen gestiftete Bibliotheken, wohl eine im Palastbereich und zumindest eine weitere im Gymnasion, die offensichtlich gemeinsam verwaltet wurden, was hier zu dem falschen Eindruck führte, daß nur eine 'Große Bibliothek' existiert hätte.

Hauptproblem und -hemmnis für die Einrichtung öffentlicher Gymnasionsbibliotheken war die Finanzierung der Bücher. Das belegen die wenigen Inschriften zu dieser Frage ein-

88 WACKER: Gymnasion, 127 f. Allgemein zu den hellenistischen Gymnasialbibliotheken: NiCOLAI, NASSAB 1, 1987, 17-48.

89 In diesem Sinne etwa jüngst wieder: VOLKer M. STROCKA: "Noch einmal zur Bibliothek von Pergamon", AA 5, 2000, 160. In diesem Zusammenhang wird immer wieder auf eine Bemerkung des Polybios rekurriert (Polyb. 12,27,4), die sich auf die arbeitstechnischen Voraussetzungen für die Abfassung eines historiographischen Werkes bezieht. Darin sieht Polybios es als unverzichtbar für die historiographische Arbeit an, daß man in unmittelbarer Nachbarschaft entweder auf ein städtisches Urkundenarchiv, das ,über einen großen Bestand an offiziellen Aufzeichnungen verfügt", oder auf irgendeine 'Bibliothek' zurückgreifen kann. Die zweite Möglichkeit wird deutlich als die schlechtere Alternative, als eine Notlösung, gekennzeichnet, denn es ist unklar, ob derartige Bibliotheken dem Historiker überhaupt geeignetes Material bieten können; darüber hinaus ist in der Stelle keinesfalls ausgesagt, daß es sich um eine öffentliche Bibliothek handeln $\mathrm{mu}$.

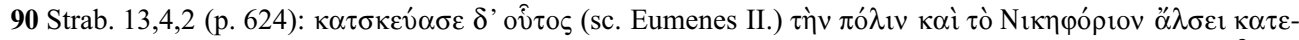

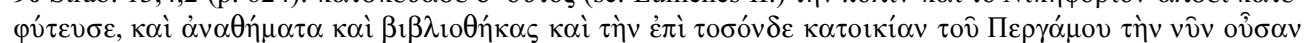

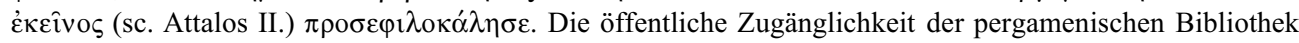
ist durch Vitr. 7 pr. 4 bezeugt (reges Attalici magnis philologiae dulcendinibus inducti cum egregiam bybliothecam Pergami ad communem delectationem instituisset).

91 Jacobsthal, MDAI(A) 33, 1908, 383 Nr. 4 (Fragment eines Dekrets?), Z. 7-10: $\tau \dot{\alpha} \delta \dot{~} \mid$ [ [-- - $\beta v] \beta \lambda_{10-}$

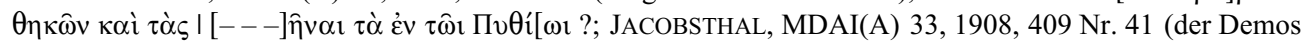
ehrt einen unbekannten Sohn des Demeas, kurz nach dem Ende der Königsherrschaft) nach der Rekonstruk-

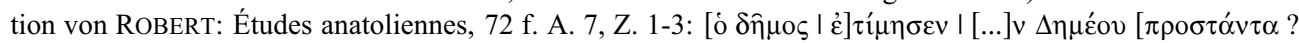
I $\tau \hat{\omega} v] \beta v \beta \lambda_{10} \theta \eta \kappa \hat{\omega}[v---$. Dieser inschriftliche Befund wird zudem von Plut. Ant. 58,9 bestätigt, wo C. Calvisius Gabinus Marcus Antonius beschuldigt, Kleopatra die pergamenischen Bibliotheken geschenkt

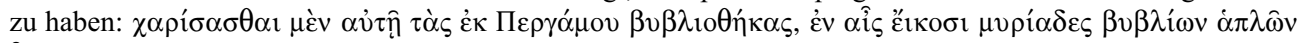
$\hat{\eta} \sigma \alpha \nu$. 
drücklich: So waren in Athen die Epheben dazu verpflichtet, Bücher zu spenden, die Bürger von Kos finanzierten mittels einer Epidosis die Einrichtung einer Bibliothek, und in Rhodos wurden die Praxis des Bücherspendens sowie die diesbezüglichen Aufgaben des Gymnasiarchen genau festgelegt, wie aus einem Inschriften-Dossier hervorgeht, in dem verschiedene Dekrete zusammengestellt waren, die sich auf die Bibliothek des örtlichen Gymnasions bezogen. ${ }^{2}$ Anhand dieses interessanten Dokuments ist die offizielle Bezeichnung für die Bibliothek glücklicherweise noch leicht zu fassen. Sie lautet: „Die Bibliothek, die die Gymnasiarchen in ihrer Obhut haben" ${ }^{93}$ In dieser Formulierung ist vorausgesetzt, daß die Bibliothek kein originärer Bestandteil der öffentlichen Institution des Gymnasions war, sondern eine später angegliederte Einrichtung, die in den Aufgabenbereich der Gymnasiarchen fiel.

Weitere Zeugnisse für Bibliotheksstiftungen bestätigen den bereits gewonnnenen Eindruck, daß öffentliche Bibliotheken tatsächlich erst seit der Mitte des 2. Jh. v. Chr. eingerichtet wurden: Durch die literarische Überlieferung ist ansonsten nur die Stiftung eines Musenheiligtums und einer Bibliothek durch Maron an seine Heimatstadt Antiochia belegt sowie die Bibliothek von Smyrna, die als eigenständige Institution neben dem Homereion genannt wird. ${ }^{94}$ Auch die wenigen epigraphischen Belege setzen erst mit dem 2. Jh. v. Chr. ein, ohne daß man eine nähere chronologische Eingrenzung vornehmen könnte. Inschriftlich sind Bibliotheken in hellenistischer Zeit nur in Athen, im Gymnasion 'Ptolemaion' (seit 117/116 v. Chr.), ${ }^{95}$ in Taormina (Anfang des 2. Jh. v. Chr.), Kos (Anfang des 2. Jh. v. Chr.), Teos (2./1. Jh. v. Chr.) und Mylasa (undatiert) bezeugt. ${ }^{96}$

$92 \mathrm{Zu}$ den Bibliotheken in Athen und Kos siehe Anm. 88-89. Zwei Fragmente eines rhodischen Bibliotheksgesetzes aus dem 2. Jh. v. Chr. sind bislang gefunden worden: (Frg. a) I. Rhod. / Kos MAIURI 4, Z. 4-7: oï

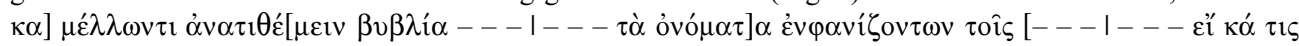

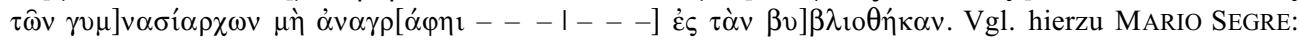
"Ancora sulla biblioteca del ginnasio di Rodi", RFIC 64, N.S. 14, 1936, 40; (Frg. b) nur angezeigt von PAPAChristodoulou, DodChron 11, 1986, 265-271; SEG 37, 1987, 699; PAPACHRISTODOUlOU, ICCA 13, 500 f. mit Tf. $75.3 \mathrm{f}$.

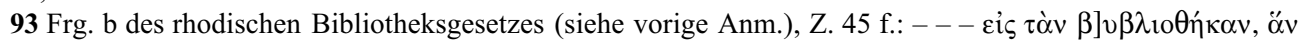

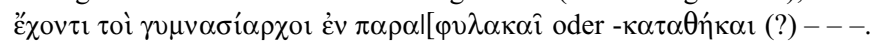

94 Maron verfügte testamentarisch den Bau einer Bibliothek in Antiocheia zwischen 150 und $100 \mathrm{v}$. Chr.: Malalas 60 (O 304, p. 235 f.) Vgl. GlanVille DowneY: A History of Antioch in Syria from Seleucus to the Arab Conquest, Princeton 1961, 132. Eine Bibliothek in Smyrna ist belegt bei: Strab. 14,1,37 (p. 646).

95 Erstmals bezeugt sind Bücherspenden eines athenischen Ephebenjahrgangs für die Bibliothek des Gymnasion Ptolemaion in IG II/III ${ }^{2} 1009$ + MERITT, Hesperia 16, 1947, 170-172 Nr. 67, Z. 30-32: „Sie (die Epheben des Jahrgangs 117/116 v. Chr.) weihten der Demeter, Kore und der Mutter der Götter eine Phiale und einhundert Bücher für die Bibliothek zum ersten Mal gemäß dem Beschluß, den Theodorides aus dem Piräus eingebracht hatte“. Vgl. PELEKIDIS: Éphébie 263 f. Weitere Erwähnung etwa in IG II/III ${ }^{2}$ 1029, Z. 26:

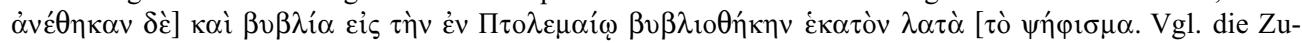
sammenstellung der Belege bei: MARIO BURZACHECHI: "Ricerche epigrafiche sulle antiche biblioteche del mondo greco", RAL VIII 18, 1963, 75-96, hier 84-87, Nr. 1-6. Die fragmentarisch erhaltene Bücherliste von IG II/III 2363 (um 100 v. Chr.) vermittelt einen Eindruck von der Auswahl der gespendeten Buchrollen, siehe hierzu neuerdings: WOLFGANG LUPPE: "Die Sophokles-Titel im Bibliothekskatalog IG II/III ${ }^{2} 2363$ ", ZPE 67, 1987, 1-4.

96 Tauromenion (Pinakes aus der Bibliothek des Gymnasions): SEG 26, 1976/77, 112 + SEG 47, 1997, 1464; Kos: LOUIS RoBerT: "Notes d'épigraphie hellénistique XLI. 'E $\pi 1 \delta$ ó $\sigma \varepsilon \imath \varsigma \varsigma$ pour les bibliothèques", BCH 59, 1935, 421-425 = Opera Minora I, 178-183; Teos (undatiertes Fragment eines Dekrets?): SEG 2, 1924, 584; Mylasa (undatiertes Fragment einer Bauinschrift): I. Mylasa I 508. 
Das allmählich ausgebildete Bedürfnis nach intellektueller Bildung war die entscheidende Voraussetzung dafür, daß nun erstmals Bibliotheken in den Gymnasien eingerichtet wurden. Als ein frühes Symptom dieser Entwicklung ist sicherlich die zeitlich ein wenig vorausgehende Einrichtung mehrerer privater Stiftungen zugunsten des Elementarunterrichts in kleinasiatischen Städten anzusehen. Darin manifestierte sich zweifellos die Bildungseuphorie der städtischen Eliten, die sich und ihre Söhne als 'gebildete' und damit auch als moralisch vorbildlich handelnde Persönlichkeiten verstanden wissen wollten. ${ }^{97} \mathrm{Die}$ im 3 . Jh. v. Chr. noch weitgehend exklusiv gehaltene Idee vom 'gebildeten Bürger' ( $\pi \varepsilon \pi \alpha 1 \delta \varepsilon v \mu \varepsilon$ 'vo / $\varphi \imath \lambda о \mu \alpha \theta \dot{n} \varsigma$ ) war damit spätestens in der Mitte des 2. Jh. v. Chr. zum Allgemeingut und zum neuen Bestandteil des griechischen Bürgerideals geworden. Seinen Endpunkt fand dieser schrittweise soziale und mentale Wandel bei der Oberschicht in der Reformierung der Ephebie zu einem exklusiven Bildungsinstitut für ein kosmopolitisches Publikum und in der Stiftung öffentlicher Bibliotheken, mit denen der Euergetismus der Reichen und Mächtigen dem neuartigen Bildungseifer Rechnung trug.

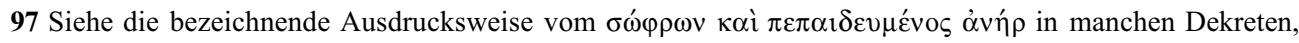
die moralisch vorbildliches Handeln mit intellektueller Schulung verknüpft. 